\title{
Preparative History vs Driving Force in Water Oxidation Catalysis: Parameter Space Studies of Cobalt Spinels
}

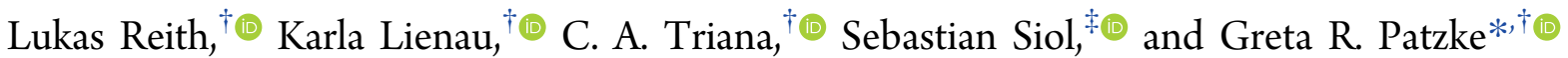 \\ ${ }^{\dagger}$ Department of Chemistry, University of Zurich, Winterthurerstrasse 190, CH-8057 Zurich, Switzerland \\ ${ }^{\ddagger}$ Empa-Swiss Federal Laboratories for Materials Science and Technology, Überlandstrasse 129, CH-8600 Dübendorf, Switzerland
}

\author{
Supporting Information
}

ABSTRACT: The development of efficient, stable, and economic water oxidation catalysts (WOCs) is a forefront topic of sustainable energy research. We newly present a comprehensive three-step approach to systematically investigate challenging relationships among preparative history, properties, and performance in heterogeneous WOCs. To this end, we studied (1) the influence of the preparative method on the material properties and (2) their correlation with the performance as (3) a function of the catalytic test method. Spinel-type $\mathrm{Co}_{3} \mathrm{O}_{4}$ was selected as a clear-cut model WOC and synthesized via nine different preparative routes. In search of the key material properties for high catalytic performance, these cobalt oxide samples were characterized with a wide

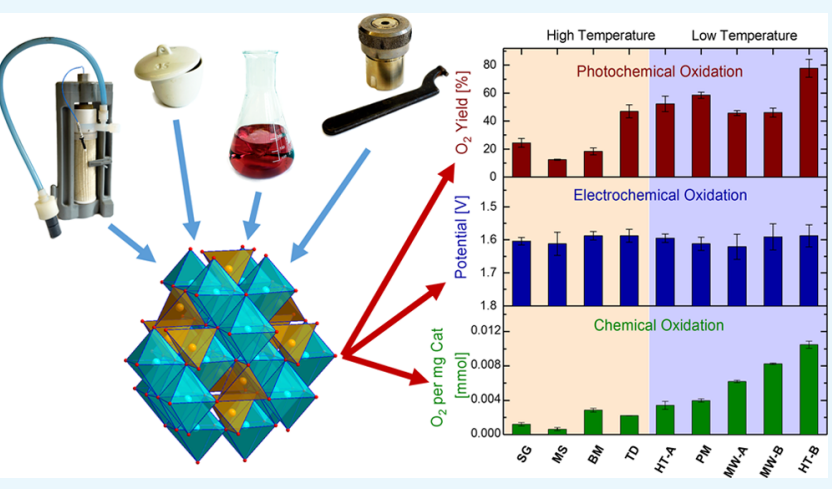
range of analytical methods, including X-ray absorption spectroscopy, X-ray photoelectron spectroscopy, powder X-ray diffraction, Raman spectroscopy, BET surface area analysis, and transmission electron microscopy. Next, the corresponding catalytic water oxidation activities were assessed with the three most widely applied protocols to date, namely, photocatalytic, electrocatalytic, and chemical oxidation. The activity of the $\mathrm{Co}_{3} \mathrm{O}_{4}$ samples was found to clearly depend on the applied test method. Increasing surface area and disorder as well as a decrease in oxidation states arising from low synthesis temperatures were identified as key parameters for high chemical oxidation activity. Surprisingly, no obvious property-performance correlations were found for photocatalytic water oxidation. In sharp contrast, all samples showed similar activity in electrochemical water oxidation. The substantial performance differences between the applied protocols demonstrate that control and comprehensive understanding of the preparative history are crucial for establishing reliable structure-performance relationships in WOC design.

\section{INTRODUCTION}

Efficient water splitting, also referred to as artificial photosynthesis, provides direct access to storable and renewable fuels. $^{1-5}$ The complex four-electron transfer of the water oxidation half reaction remains a major bottleneck for designing high-performance water splitting systems. ${ }^{6}$ Therefore, the development of stable, economic, and efficient water oxidation catalysts (WOCs) is essential for water splitting technologies. 7,8

However, the quest for optimal WOCs remains largely empirical due to fundamental open questions in solid-state synthesis. First, the predictivity of inorganic synthetic protocols is still limited, especially with respect to understanding the precise influence of diverse synthetic methods and conditions on crucial material parameters. ${ }^{9-13}$ Consequently, establishing predictive preparation-properties-performance relations for WOCs remains a fundamental challenge. Moreover, recent results indicate that the key parameters required for optimal WOC performance can vary significantly with the applied catalytic test method. ${ }^{14-16}$ Few systematic studies to date shed light on the understanding of preparative history as an essential foundation for catalyst production, which is indispensable for true material tailoring and any large-scale production processes. In the long term, screening such wide parameter spaces may only be possible with new, tailored machine learning approaches. ${ }^{17,18}$

We here introduce a new, comprehensive strategy to investigate the complex interplay of preparation, emerging properties, and assay-dependent performance for $\mathrm{Co}_{3} \mathrm{O}_{4}$ as a straightforward, binary WOC model system.

In the ongoing search for abundant, low-cost, and robust alternatives to noble metals, ${ }^{16,7}$ spinel-type $\mathrm{Co}_{3} \mathrm{O}_{4}$ keeps attracting attention. ${ }^{19-21}$ Furthermore, $\mathrm{Co}_{3} \mathrm{O}_{4}$ is investigated for a wide range of other applications, for example, in battery electrodes, ${ }^{22-24}$ sensors, ${ }^{25}$ data storage, ${ }^{26}$ as well as in general heterogeneous catalysis. ${ }^{27,28}$ Therefore, considerable attempts have been made to improve the oxygen evolution reaction (OER) performance of pristine $\mathrm{Co}_{3} \mathrm{O}_{4}$, which is limited by

Received: June 7, 2019

Accepted: August 28, 2019

Published: September 13, 2019 

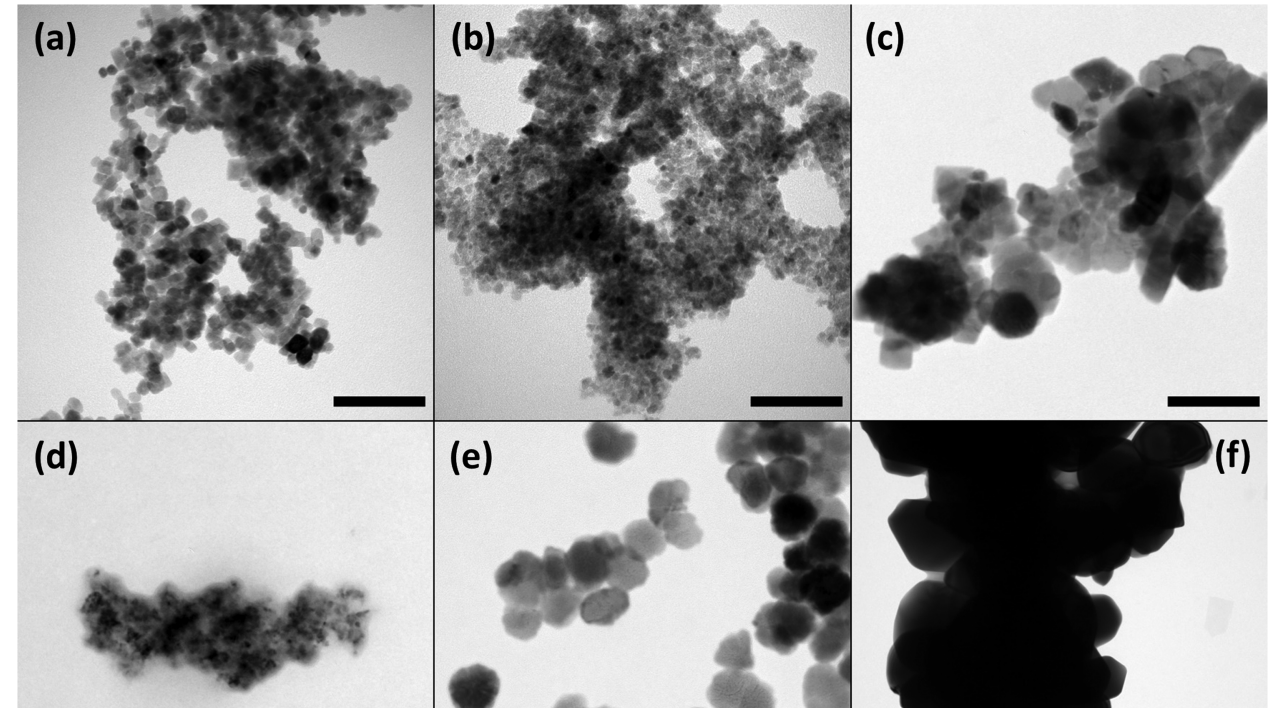

(e)
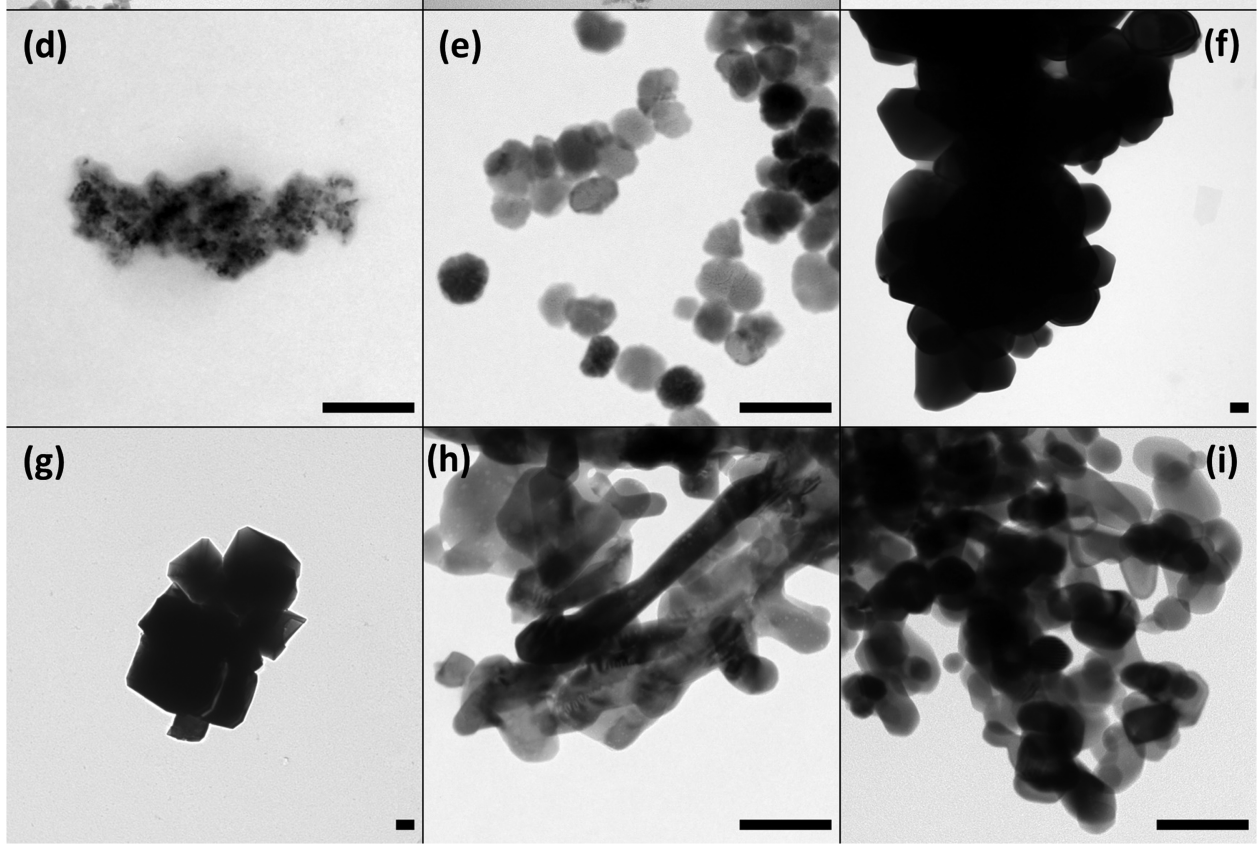

Figure 1. TEM images of representative $\mathrm{Co}_{3} \mathrm{O}_{4}$ samples prepared by different synthesis methods: (a) MW-A, (b) MW-B, (c) HT-A, (d) HT-B, (e) PM, (f) SG, (g) MS, (h) BM, and (i) TD (scale bar $=80 \mathrm{~nm}$ ).

conductivity and the number of exposed surface active sites. ${ }^{29}$ To this end, various specific properties were addressed, such as crystallinity, $^{30,31}$ oxidation states, ${ }^{32,33}$ particle/crystallite size, ${ }^{34,35}$ defects, ${ }^{36}$ crystal structure, $^{37-40}$ surface area, ${ }^{41}$ and morphology. ${ }^{42,43,29}$ Defects in particular can exert a great influence on the interaction between the reactants and the catalyst surface. ${ }^{44-48}$ While oxygen defects in $\mathrm{Co}_{3} \mathrm{O}_{4}$ created a higher amount of active $\mathrm{Co}$ (II) surface species, cobalt deficiencies were found to enhance the surface wettability. ${ }^{44,45}$ Furthermore, the productive influence of edge dislocation defects on the electrochemical performance of $\mathrm{Co}_{3} \mathrm{O}_{4}$ was newly explored. ${ }^{49}$ Additionally, a wide range of different synthetic methods was applied on $\mathrm{Co}_{3} \mathrm{O}_{4}$ in the course of individual studies, including molten salt (MS), ${ }^{50}$ ball milling (BM), ${ }^{51}$ sol-gel (SG), ${ }^{52}$ thermal decomposition (TD), ${ }^{53,54}$ precipitation, ${ }^{55}$ and classic/microwave hydrothermal (MW) synthesis. $^{56,57,21}$

Generally, deriving clear preparation-performance trends from comparisons between different studies remains difficult due to the underlying variations in the obtained material properties. $^{58-60}$ To the best of our knowledge, the impact of the manifold preparative options on the catalytic efficiency of $\mathrm{Co}_{3} \mathrm{O}_{4}$ in different test methods has not been evaluated coherently to date. The three most common routine tests are (1) photochemical oxidation with the well-established [Ru(bpy) $\left.{ }_{3}\right]^{2+} / \mathrm{S}_{2} \mathrm{O}_{8}{ }^{2-} /$ visible-light assay, (2) chemical oxidation, typically performed with ceric ammonium nitrate (CAN), and (3) electrochemical methods. ${ }^{15,61-63}$ More emphasis in electrochemical catalysis was hitherto placed on identifying the true active species for Co-oxide-assisted water oxidation. ${ }^{64-67}$ Recently, two in situ studies revealed that the observed process was in fact reversible and associated with the formation of a cobalt oxyhydroxide layer during electrocatalysis. $^{31,32,67}$

Notwithstanding, critical comparisons between two or more catalytic test assays for a given WOC remain quite rare, so that activity trends for one assessment method were often assumed to be valid for another. Only in 2015 , a pioneering study by Stahl et al. ${ }^{14}$ first critically evaluated the influence of the employed oxidation method on the activity of different manganese oxide WOCs and demonstrated that the "best catalyst" indeed depends on the applied oxidation method. Furthermore, Ding et al. ${ }^{68,69}$ found a related dependence on the applied protocol for iron-based oxides doped with different elements and iron-based polyoxometalates. These results on select systems demonstrate the general necessity for further studies into the complex parameter space of catalyst preparation, properties, and test protocols.

We here pave new ways to assess WOCs unambiguously with a systematic three-step methodology that stands out through screening a wide synthetic parameter space for emerging properties-performance relations. $\mathrm{Co}_{3} \mathrm{O}_{4}$ as a 
Table 1. Specific Surface Area of the Synthesized Cobalt Oxides Determined from the Brunauer-Emmet-Teller (BET) Model and the Crystallite Domain Size $\tau_{\mathrm{XRD}}$, Calculated from the Scherrer Equation

\begin{tabular}{|c|c|c|c|c|c|c|c|c|c|}
\hline & MW-A & MW-B & HT-A & HT-B & PM & SG & MS & $\mathrm{BM}$ & TD \\
\hline $\operatorname{BET}\left(\mathrm{m}^{2} / \mathrm{g}\right)$ & 99 & 146 & 18 & 203 & 42 & 28 & 2 & 8 & 11 \\
\hline$\tau_{\mathrm{XRD}}{ }^{a}(\mathrm{~nm})$ & $7.3 \pm 0.1$ & $11.3 \pm 0.3$ & $97 \pm 14$ & $8.1 \pm 1.3$ & $25 \pm 2.0$ & $91 \pm 27$ & $141 \pm 20$ & $126 \pm 35$ & $108 \pm 28$ \\
\hline
\end{tabular}

${ }^{a}$ It should be noted that the instrumental broadening becomes the limiting factor for calculations of very narrow full width at half-maximum (FWHM) values and therefore large crystallite domain sizes.

(a)

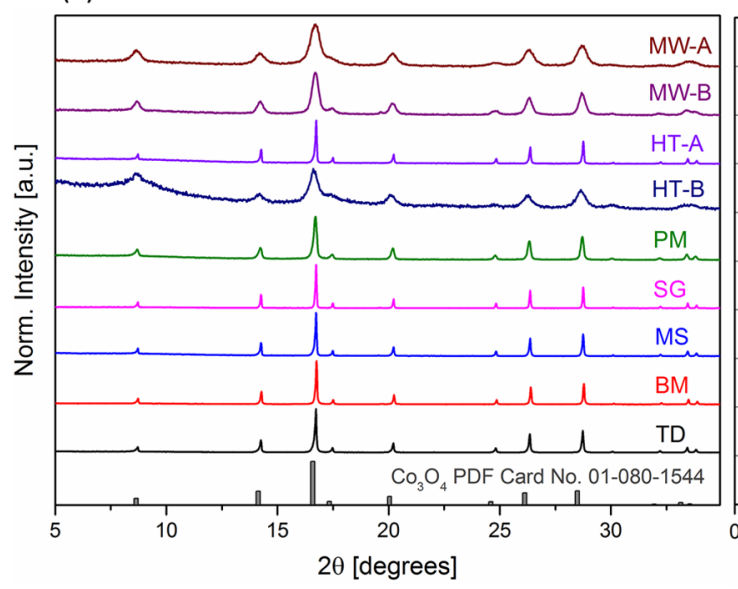

(b)

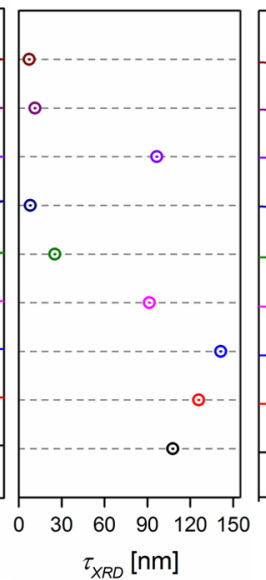

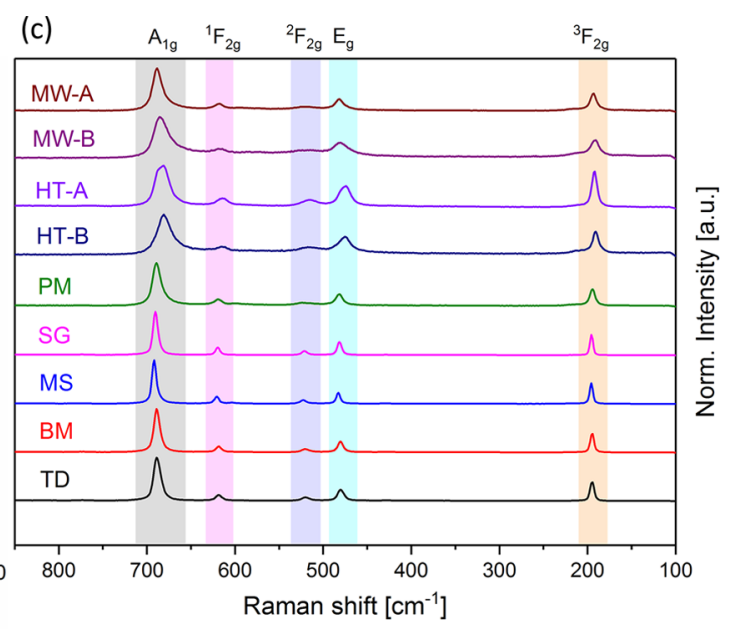

Figure 2. (a) PXRD patterns of spinel $\mathrm{Co}_{3} \mathrm{O}_{4}$ synthesized by different methods. (b) Calculated crystallite domain size $\tau_{\mathrm{XRD}}$ at FWHM. (c) Raman spectra of the synthesized spinel cobalt oxides.

model WOC was (1) accessed with a wide spectrum of synthetic methods. (2) The influence of these preparative routes on the WOC activity was specifically assessed with the three most established catalytic test methods. (3) The emerging properties-performance trends were then substantiated with thorough syncharacterizations of the different $\mathrm{Co}_{3} \mathrm{O}_{4}$ materials with a wide analytical repertoire, including surface analyses, diffraction, spectroscopy, and microscopy techniques. This strategy brought forward new correlations between the preparative history of $\mathrm{Co}_{3} \mathrm{O}_{4}$ specimens with both their resulting material properties and the catalytic performance in different water oxidation setups.

\section{RESULTS AND DISCUSSION}

Characterization of the Different $\mathrm{Co}_{3} \mathrm{O}_{4}$ Materials. The synthesized cobalt oxides were labeled according to the applied synthesis method: microwave hydrothermal (MW), hydrothermal (HT), precipitation method (PM), sol-gel (SG), molten salt (MS), ball milling (BM), and thermal decomposition (TD). Further information on the specific synthetic protocols is provided in the Experimental Section and Methods.

Transmission Electron Microscopy (TEM) and BrunauerEmmett-Teller (BET) Surface Area Characterizations. Representative TEM images of $\mathrm{Co}_{3} \mathrm{O}_{4}$ samples emerging from the nine different synthetic protocols are shown in Figure 1. The synthetic methods exerted a clear influence on the resulting morphologies. The spinel cobalt oxides prepared by (microwave) hydrothermal synthesis (Figure 1a,b,d) and by the precipitation method (Figure 1e) show agglomerated nanoparticles in a size range $5-15$ and $25 \mathrm{~nm}$, respectively. The $\mathrm{Co}_{3} \mathrm{O}_{4}$ samples synthesized by a different hydrothermal procedure or by ball milling and thermal decomposition (Figure 1c,h,i) partially consist of elongated nanoparticles with an average size distribution around $50 \mathrm{~nm}$. The particles shown in Figure 1f,g were prepared by sol-gel and molten salt methods, respectively, and they exhibit significantly larger particle sizes of more than $300 \mathrm{~nm}$.

Furthermore, the surface area values of all samples were determined from their measured $\mathrm{N}_{2}$-sorption isotherms with the Brunauer-Emmet-Teller (BET) model. The values are given in Table 1 and are in line with the TEM images, as well as with the general trend of smaller particles showing a higher surface area and vice versa.

Powder X-ray Diffraction (PXRD). The powder X-ray diffraction (PXRD) data in Figure 2a show the patterns for all synthesized $\mathrm{Co}_{3} \mathrm{O}_{4}$ samples that display the spinel-type structure throughout (space group $F \bar{d} m$ (No.: 227)). In the normal spinel structure, the $\mathrm{O}^{2-}$ anions form a cubic closepacked lattice, where octahedral and tetrahedral sites are occupied by the $\mathrm{Co}^{3+}$ and $\mathrm{Co}^{2+}$ cations, respectively. ${ }^{70}$ Although all Bragg reflections are in agreement with the given reference (PDF Card No.: 01-080-1544), the full width at half-maximum (FWHM) is different for all synthesized cobalt oxides. As the crystallite domain size $\tau_{\mathrm{XRD}}$ correlates with the FWHM, the Scherrer equation ${ }^{71}$ was used to calculate $\tau_{\mathrm{XRD}}$ as shown in Figure $2 \mathrm{~b}$ and Table $1 .^{70}$ As expected, the cobalt oxides synthesized at higher temperatures $\left(\geq 400{ }^{\circ} \mathrm{C}\right)$, namely, SG, MS, BM, and TD, display a high crystallite domain size from $\approx 91 \mathrm{~nm}$ (SG) and up to $\approx 141 \mathrm{~nm}(\mathrm{MS})$. The cobalt oxide samples obtained at lower temperatures $\left(\leq 180{ }^{\circ} \mathrm{C}\right)$, that is, MW-A, MW-B, HT-B, and PM, show a much lower crystallite domain size with values below $\approx 25 \mathrm{~nm}$ $(\mathrm{PM})$ and down to $\approx 7 \mathrm{~nm}$ (MW-A). HT-A is the only exception to this trend with a higher $\tau_{\mathrm{XRD}}$ of $\approx 96 \mathrm{~nm}$.

Raman Spectroscopy and PXRD Characterization. The Raman spectra of all synthesized cobalt oxides are shown in Figure 2c. The group theory predicts five Raman-active 
vibrational modes for $\mathrm{Co}_{3} \mathrm{O}_{4}$, consisting of $\mathrm{A}_{1 \mathrm{~g}}, \mathrm{E}_{\mathrm{g}}$, and three $\mathrm{F}_{2 \mathrm{~g}}$ modes. $^{72}$ These five main phonon excitations were observed for all spectra and match well with theoretical and experimental reports on spinel-type cobalt oxide. ${ }^{73,74}$ The symmetric $\mathrm{Co}^{3+}-\mathrm{O}$ stretching vibration of octahedrally coordinated $\mathrm{CoO}_{6}$ is attributed to $\mathrm{A}_{1 \mathrm{~g}}$ in ${ }^{7} \mathrm{O}_{h}$ symmetry and is assigned to the most intense band at $\approx 690 \mathrm{~cm}^{-1}$. The medium-/low-intensity bands at $\approx 620, \approx 520$, and $\approx 480 \mathrm{~cm}^{-1}$ correspond to ${ }^{1} \mathrm{~F}_{2 \mathrm{~g}}{ }^{2} \mathrm{~F}_{2 \mathrm{~g}}$, and $\mathrm{E}_{\mathrm{g}}$ symmetry. The band at $\approx 190$ $\mathrm{cm}^{-1}$ arises from tetrahedrally coordinated $\mathrm{Co}^{2+} \mathrm{O}_{4}$ units with ${ }^{3} \mathrm{~F}_{2 \mathrm{~g}}$ symmetry. These results further confirm the formation of phase-pure cubic spinel $\mathrm{Co}_{3} \mathrm{O}_{4}$ from all applied synthesis methods.

Generally, narrow and intense Raman-active modes are indicative of well-ordered structures. In the present system, the oxides emerging from low-temperature methods (MW-A, MWB, HT-B, PM) exhibit Raman peaks shifted toward higherfrequency values. They display lower intensity and peak broadening (Table S1) when compared with the oxide samples obtained at higher temperatures (SG, MS, BM, TD). This trend indicates a decrease in the long-range order of oxides synthesized at low temperatures (MW-A, MW-B, HT-B, PM). Likewise, their PXRD patterns display low intensities and peak broadening (MW-A, MW-B, HT-B, P, Figure 2a). ${ }^{75}$ Among them, the pattern of $\mathrm{Co}_{3} \mathrm{O}_{4}-\mathrm{HT}-\mathrm{B}$ shows tremendous peak broadening. This can be explained by the smaller particle size and increased disorder as described below.

The observed variations in the Raman symmetry and PXRD patterns further suggest that the tetrahedral and octahedral coordination environments in the different $\mathrm{Co}_{3} \mathrm{O}_{4}$ specimens depend on the applied synthetic methods. The irregular cation distribution induces lattice distortions and residual stress in the spinel structure, which could result from the formation of oxygen or cobalt vacancies and weaken the average $\mathrm{Co}-\mathrm{O}$ bond strength. $^{76}$

X-ray Absorption Spectroscopy (XAS). To acquire deeper insights into the atomic short-range order of the as-synthesized cobalt oxides, X-ray absorption near-edge structure (XANES) and extended X-ray absorption fine structure (EXAFS) analyses were carried out. Figure 3 shows the fitting of the Fourier-transform (FT) $\left|k^{3} \chi(k)\right|$ spectra of the experimental Co K edge EXAFS spectra $k^{3} \chi(k)$, for oxides displaying remarkable differences in their short-range order, that is, $\mathrm{Co}_{3} \mathrm{O}_{4}-\mathrm{SG},-\mathrm{MS}$, -PM, -MW-A, -MW-B, and -HT-B. The $\mathrm{Co}_{3} \mathrm{O}_{4}-\mathrm{BM}$, -TD, and -HT-A oxides show a short-range order similar to that of $\mathrm{Co}_{3} \mathrm{O}_{4}-\mathrm{PM}$, and the fitting results of their $\mathrm{FT}\left|k^{3} \chi(k)\right|$ spectra are presented in Figure S2. Calculated main values for interatomic distances, atomic coordination numbers $(N)$, and Debye-Waller factors $\left(\sigma^{2}\right)$ are given in Table S2.

All synthesized $\mathrm{Co}_{3} \mathrm{O}_{4}$ samples show four prominent peaks arising from backscattering of neighboring $\mathrm{O}$ and Co atoms. The first peak in the $\mathrm{FT}\left|k^{3} \chi(k)\right|$ spectra at $r \approx 1.55 \AA$ relates to $\mathrm{Co}^{2+}$ and $\mathrm{Co}^{3+}$ cations in tetrahedral $\left\{\mathrm{CoO}_{4}\right\}$ and octahedral $\left\{\mathrm{CoO}_{6}\right\}$ coordination with oxygen atoms at interatomic distances of $\approx 1.914$ and $\approx 1.899 \AA$, respectively. However, since those two shells are too close to be resolved in the FTl $k^{3} \chi(k) \mid$ spectra, they convolute to a first $\mathrm{Co}-\mathrm{O}$ shell with a main interatomic distance $\mathrm{Co}-\mathrm{O} \approx 1.907 \AA$ and an averaged atomic coordination number $N=5.333$. The second and third peaks in the $\mathrm{FT}\left|k^{3} \chi(k)\right|$ spectra, at $r \approx 2.49$ and $2.95 \AA$, correspond to the $\mathrm{Co}_{\text {Octa }}-\mathrm{Co}_{\text {Octa }} \approx 2.86 \AA[N=4]$ and $\mathrm{Co}_{\text {Tetra }}-\mathrm{Co}_{\text {Octa }} \approx 3.35 \AA[N=8]$ coordination shells. The fourth peak at $r \approx 4.70 \AA$ relates to higher $\mathrm{Co}$ and $\mathrm{O}$

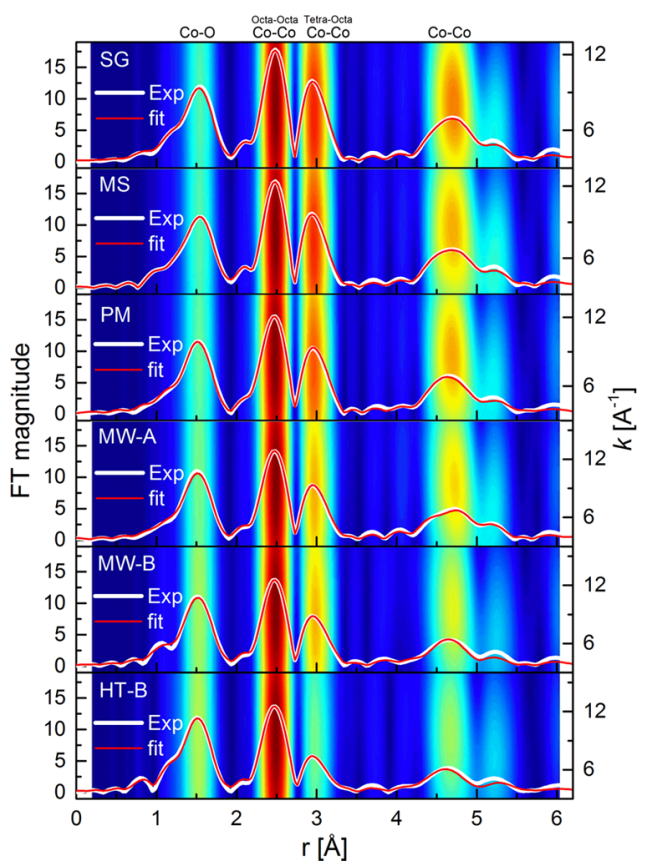

Figure 3. Fitting (colored spectra) of the Fourier-transform $\mathrm{FT}\left|k^{3} \chi(k)\right|$ of the experimental Co $\mathrm{K}$ edge EXAFS spectra $k^{3} \chi(k)$ (gray) of $\mathrm{Co}_{3} \mathrm{O}_{4}-\mathrm{SG}$, -MS, -PM, -MW-A, -MW-B, and -HT-B, phase uncorrected. The background two-dimensional contour plots are the wavelet-transform (WT) of the $k^{3} \chi(k)$ spectra, and their shaded regions highlight the decrease of the peak intensity associated with the increasing disorder parameter $\sigma^{2}$ for $\mathrm{Co}-\mathrm{O}, \mathrm{Co}_{\mathrm{Octa}}-\mathrm{Co}_{\mathrm{Octa}} \mathrm{Co}_{\mathrm{Tetra}}-$ $\mathrm{Co}_{\text {Octa }}$, and higher $\mathrm{Co}-\mathrm{Co}(-\mathrm{O})$ coordination shells.

coordination shells (Figure 3 and Table S2). Remarkably, while the relative amplitude of the first $\mathrm{Co}-\mathrm{O}$ coordination shell in the $\mathrm{FT}\left|k^{3} \chi(k)\right|$ and wavelet-transform (WT) spectra $(r$ $\approx 1.55 \AA$ ) does not change much among the different $\mathrm{Co}_{3} \mathrm{O}_{4}$ oxides, the $\mathrm{FT}^{3} k^{3}(k) \mid$ and WT spectra show a decreasing relative magnitude of the $\mathrm{Co}_{\text {Octa }}-\mathrm{Co}_{\text {Octa }}, \mathrm{Co}_{\text {Tetra }}-\mathrm{Co}_{\text {Octa }}$ and higher $\mathrm{Co}-\mathrm{Co}(-\mathrm{O})$ coordination peaks from high- to lowtemperature synthesis methods in the order $\mathrm{Co}_{3} \mathrm{O}_{4}-\mathrm{SG}>-\mathrm{MS}$ $>-\mathrm{PM}>-\mathrm{MW}-\mathrm{A}>-\mathrm{MW}-\mathrm{B}>-\mathrm{HT}-\mathrm{B}$ (Figure 3 ).

The amplitude decay in the $\mathrm{FTT}^{3} \chi(k) \mid$ and WT spectra is correlated with a decrease of the coordination number or an increase in the mean-square disorder parameter $\sigma^{2}=\sigma_{\text {thermal }}^{2}+$ $\sigma_{\text {static }}^{2}$ that is, Debye-Waller factors. Here, structural disorder arises from static disorder $\sigma_{\text {static }}^{2}$ that is, crystal defects due to slightly different interatomic distances in the same coordination shell. The vibrational disorder $\sigma_{\text {thermal }}^{2}$ is not crucial since the spectra have been all measured at the same temperature. Hence, the decline in the relative amplitude of high coordination peaks in the $\mathrm{FT}\left|k^{3} \chi(k)\right|$ and WT spectra provides a direct indication of the extent of crystalline long-range order around the cobalt centers. The results in Figure 3 and Table S2 suggest the existence of static disorder and the presence of Co and $\mathrm{O}$ vacancies in the structure of the cobalt oxides synthesized at low temperature, namely, $\mathrm{Co}_{3} \mathrm{O}_{4}-\mathrm{HT}-\mathrm{B},-\mathrm{MW}$ $\mathrm{B},-\mathrm{MW}-\mathrm{A}$, and -PM. While the atomic coordination number $\mathrm{N}$ for $\mathrm{Co}_{\text {Octa }}-\mathrm{Co}_{\text {Octa }}, \mathrm{Co}_{\text {Tetra }}-\mathrm{Co}_{\text {Octa }}$ and higher $\mathrm{Co}-\mathrm{Co}(-\mathrm{O})$ coordination shells remains quite the same for $\mathrm{Co}_{3} \mathrm{O}_{4}-\mathrm{SG},-\mathrm{MS}$, -PM, -BM, -TD, and -HT-A, the mean-square disorder $\sigma^{2}$ of those oxides increases steadily (Figures S1, S2, and Table S2). The static local disorder $\sigma^{2}$ increases most notably for $\mathrm{Co}_{3} \mathrm{O}_{4}$ MW-A, -MW-B, and -HT-B. Additionally, for those oxide 
materials, the atomic coordination number $\mathrm{N}$ of the $\mathrm{Co}-\mathrm{O}$, $\mathrm{Co}_{\text {Octa }}-\mathrm{Co}_{\text {Octa }}, \mathrm{Co}_{\mathrm{Tetra}}-\mathrm{Co}_{\text {Octa }}$, and higher $\mathrm{Co}-\mathrm{Co}(-\mathrm{O})$ coordination shells is slightly smaller than the corresponding values of the more crystalline samples $\mathrm{Co}_{3} \mathrm{O}_{4}$-SG, -MS, and -PM. The $\mathrm{Co}-\mathrm{O}$ bond length of $\approx 1.912 \AA$ in $\mathrm{Co}_{3} \mathrm{O}_{4}$-MW-A is slightly larger with respect to the other oxides, suggesting lattice expansion and relaxation of $\mathrm{Co}-\mathrm{O}$ bonds. These findings agree with results from PXRD and Raman spectra, in which $\mathrm{Co}_{3} \mathrm{O}_{4}-\mathrm{MW}-\mathrm{A},-\mathrm{MW}-\mathrm{B}$, and -HT-B show lower intensity and broadened diffraction and Raman peaks due to the local structural dispersion of the $\mathrm{Co}$ and $\mathrm{O}$ atoms in the spinel structure (Figure 2a,c).

Figure 4a shows XANES spectra for as-synthesized $\mathrm{Co}_{3} \mathrm{O}_{4}$ SG, -MS, -PM, -MW-A, -MW-B, and -HT-B and those of the

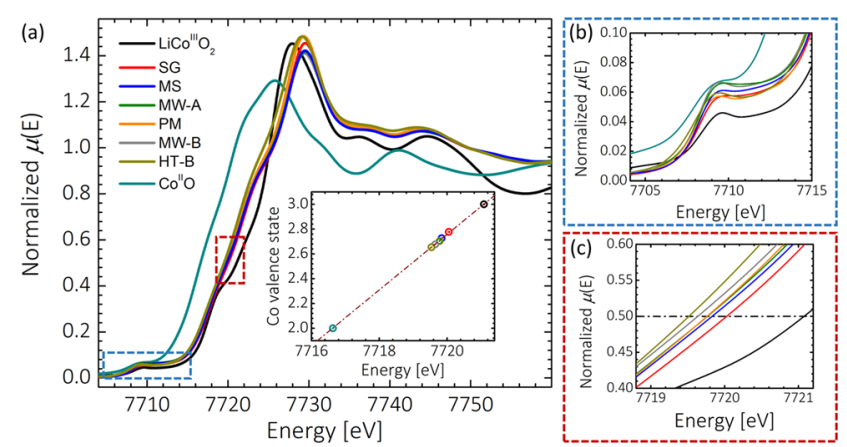

Figure 4. (a) XANES spectra of synthesized $\mathrm{Co}_{3} \mathrm{O}_{4}-\mathrm{SG}$, -MS, -PM, -MW-A, -MW-B, and -HT-B oxides and reference compounds $\mathrm{Co}^{\mathrm{II}} \mathrm{O}$ and $\mathrm{LiCo}^{\mathrm{III}} \mathrm{O}_{2}$. The inset shows the calculated Co valence states, (b) zoom of changes in the pre-edge intensity of XANES spectra, and (c) zoom of the shifts of the Co $\mathrm{K}$ edge absorption edge to higher energies at $\mu(E)=0.5$ of the normalized XANES spectra.

reference compounds $\mathrm{Co}^{\mathrm{II}} \mathrm{O}$ and $\mathrm{LiCo}^{\mathrm{III}} \mathrm{O}_{2}$. The cobalt $\mathrm{K}$ edge absorption edge is gradually shifted to higher energy from $\approx 7719.1 \mathrm{eV}$ for $\mathrm{Co}_{3} \mathrm{O}_{4}$-HT-B to $\approx 7720.36 \mathrm{eV}$ for $\mathrm{Co}_{3} \mathrm{O}_{4}-\mathrm{SG}$ (Figure 4c), which suggests that the distinct $\mathrm{Co}_{3} \mathrm{O}_{4}$ oxides were slightly oxidized when proceeding from low to high synthesis temperatures. The average oxidation state of Co was estimated from the linear dependence of the Co $\mathrm{K}$ edge position at the energy corresponding to a $\mu(E)$-value of 0.5 of the normalized XANES spectra. ${ }^{77}$ Consequently, the insets in Figures $4 \mathrm{a}$ and $\mathrm{S} 3 \mathrm{~b}$ show that based on the absorption edge energy position $(\mu(E) \approx 0.5)$ of the reference compounds $\mathrm{Co}^{\mathrm{II}} \mathrm{O}$ and $\mathrm{LiCo}^{\mathrm{III}} \mathrm{O}_{2}$, the Co valence states for the synthesized $\mathrm{Co}_{3} \mathrm{O}_{4}$ oxides slightly increase from $\approx 2.654$ for $\mathrm{Co}_{3} \mathrm{O}_{4}$-HT-B to $\approx 2.778$ for $\mathrm{Co}_{3} \mathrm{O}_{4}$-SG. The average cobalt oxidation state in an ideal spinel is 2.67. To preserve electroneutrality, $\mathrm{O}^{2-}$ vacancies can for example be balanced by two $\mathrm{Co}^{2+}$ sites replacing two $\mathrm{Co}^{3+}$ centers, resulting in an overall decrease of the average cobalt oxidation state. In the case of cobalt defects (or interstitial oxygen), the missing charge of a $\mathrm{Co}^{2+/ 3+}$ site (or an additional $\mathrm{O}^{2-}$ charge) can be balanced by two/three $\mathrm{Co}^{3+}$ sites instead of two/three $\mathrm{Co}^{2+}$ sites, giving rise to a higher average cobalt oxidation state. ${ }^{44,45}$

As shown in Figure $4 \mathrm{~b}$, the XANES spectra of the synthesized oxides exhibit a characteristic pre-edge peak at about $\approx 7709.6 \mathrm{eV}$, whose intensity slightly increases in the order $\mathrm{Co}_{3} \mathrm{O}_{4}$-MW-B $>-\mathrm{MW}-\mathrm{A}>-\mathrm{MS}>-\mathrm{HT}-\mathrm{B}>-\mathrm{PM}>-\mathrm{SG}$. The pre-edge peak in XANES spectra is more intense for metal centers in tetrahedral symmetry and becomes broader and less intense for metal centers in octahedral coordination. ${ }^{77}$ Hence, the results in Figure $4 \mathrm{~b}$ suggest that the cobalt distribution over the tetrahedral and octahedral sites, that is, the degree of inversion $x$, could be slightly different among the synthesized oxides. Quantitative values of the degree of inversion $x$ can be obtained from EXAFS fitting by weighting the amplitude of the scattering paths computed when the absorbing Co atom is located at the tetrahedral or octahedral sites. A single variable $x$ corresponding to the degree of inversion was used as a fitting parameter multiplying the amplitude reduction factor $S_{0}{ }^{2}$ of computed scattering paths from tetrahedral or octahedral sites. The calculated values for the degree of inversion $x$ for all synthesized $\mathrm{Co}_{3} \mathrm{O}_{4}$ spinel oxides are given in Table S2. The values of $x$ range from $x=0.07 \pm 0.02$ for $\mathrm{Co}_{3} \mathrm{O}_{4}$-SG to $x=$ $0.18 \pm 0.02$ for $\mathrm{Co}_{3} \mathrm{O}_{4}-\mathrm{MW}-\mathrm{B}$. These values agree with earlier reported data of inversion degrees $x$ for spinel $\mathrm{Co}_{3} \mathrm{O}_{4}$ oxides. $^{78,79}$ The computed low $x$ values for $\mathrm{Co}_{3} \mathrm{O}_{4}$-SG, -MS, -PM, and -HT-B suggest that those $\mathrm{Co}_{3} \mathrm{O}_{4}$ oxides adopt the normal spinel structure. The slightly higher values of $x$ for $\mathrm{Co}_{3} \mathrm{O}_{4}$-MW-A and MW-B could suggest a slightly inverted spinel structure. While the energy position and line shape of the white line intensity in the XANES spectra are sensitive to experimental beam stability, the change in the white line intensity and the slight shift to lower energy (Figure S3a) further indicate the presence of structural disorder and an increase of the inversion degree $x$. This result also suggests that the densities of unoccupied d-states and oxidation states of $\mathrm{Co}$ atoms are indeed different among the synthesized $\mathrm{Co}_{3} \mathrm{O}_{4}$-SG, -MS, -PM, -MW-A, -MW-B, and -HT-B oxides. These trends agree with those of PXRD and Raman spectra and indicate that low-temperature synthesis of $\mathrm{Co}_{3} \mathrm{O}_{4}$ promotes the formation of a charge imbalance, $\mathrm{Co}$ and/or $\mathrm{O}$ vacancies, or unsaturated chemical bonds on the spinel surface structure.

$X$-ray Photoelectron Spectroscopy (XPS). XPS data for $\mathrm{Co}_{3} \mathrm{O}_{4}-\mathrm{MW}-\mathrm{B},-\mathrm{HT}-\mathrm{B},-\mathrm{SG}$, and -PM are shown in Figure 5 together with those of the reference samples $\mathrm{Co}^{\mathrm{II}} \mathrm{O}$ and $\mathrm{LiCo}^{\mathrm{III}} \mathrm{O}_{2}$ for representative core-level spectra of $\mathrm{Co}^{2+}$ and $\mathrm{Co}^{3+}$, respectively. The binding energies of the Co $2 \mathrm{p}_{3 / 2}$ emission are similar for all investigated cobalt oxides at $\approx 780$ $\mathrm{eV}$ (Figure 5a), which is in good agreement with literature reports. ${ }^{80}$ Whereas the peak positions for $\mathrm{Co}^{2+}$ and $\mathrm{Co}^{3+}$ are hard to distinguish, samples containing $\mathrm{Co}^{2+}$ show an additional characteristic shake-up satellite emission at roughly $786 \mathrm{eV}^{81}$ The intensity of this satellite emission (inset of Figure 5a) can be used to assess the relative amount of $\mathrm{Co}^{2+}$ present in the sample. Postcatalytic analysis of $\mathrm{Co}_{3} \mathrm{O}_{4}$-HT-B therefore reveals a small decrease in the relative $\mathrm{Co}^{2+}$ amount (Figure S5). By comparing the intensity of the satellite emission of the synthesized cobalt oxides with that of the reference compounds $\mathrm{LiCo}^{\mathrm{III}} \mathrm{O}_{2}$ and $\mathrm{Co}^{\mathrm{II}} \mathrm{O}$, the following trend for the average Co valence states was derived: $\mathrm{HT}-\mathrm{B}<\mathrm{PM} \approx$ $\mathrm{MW}-\mathrm{B}<\mathrm{SG}$. This trend is in good agreement with the XANES data shown in Figure $4 a, c$. Whereas the Co $2 \mathrm{p}_{3 / 2}$ core-level binding energies are similar for $\mathrm{CoO}$ and $\mathrm{Co}_{3} \mathrm{O}_{4}$, the shift in the kinetic energy of the L $3 \mathrm{VV}$ Auger emission is considerable for different oxidation states. Figure $5 \mathrm{~b}$ shows a Wagner plot featuring both Co $2 \mathrm{p}_{3 / 2}$ binding energies and L3VV Auger kinetic energies. The Wagner plot is a helpful analytical tool for chemical state analysis because it provides a comprehensive display of both Auger electron kinetic energies and photoelectron binding energies. It can be applied for different materials containing the same element by plotting the kinetic energies of an Auger peak over the binding energies of a photoelectron peak. ${ }^{82}$ The sum of the Auger kinetic energies 
(a)

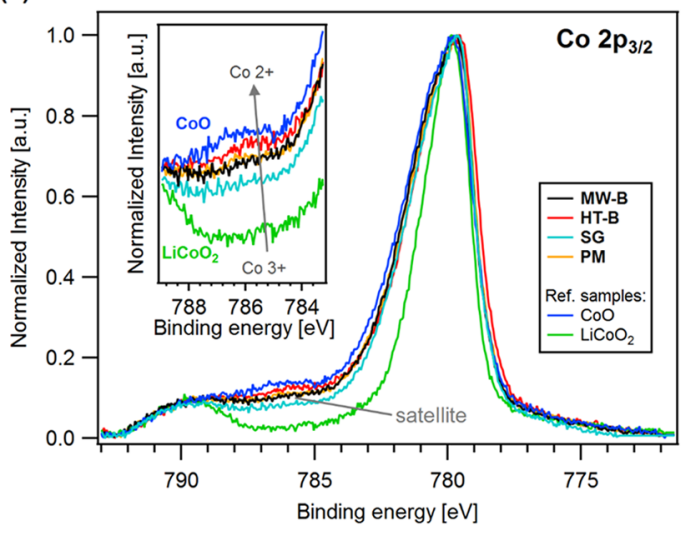

(b)

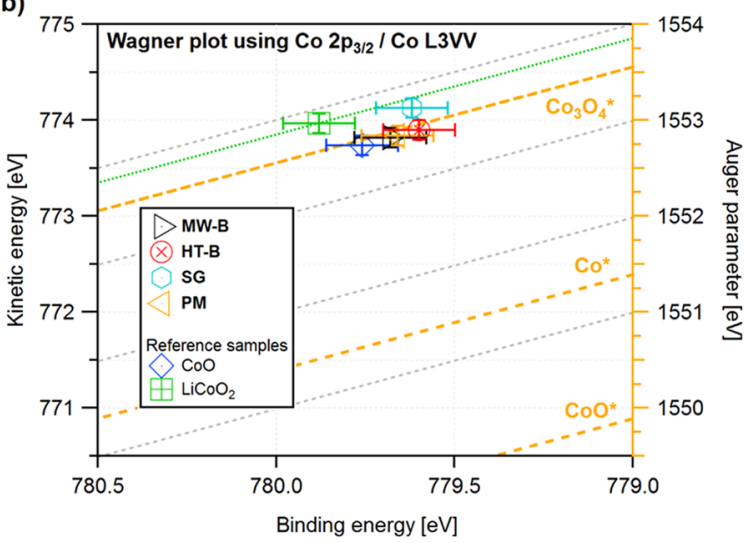

Figure 5. (a) XPS spectra of the Co $2 \mathrm{p}_{3 / 2}$ peak of the synthesized $\mathrm{Co}_{3} \mathrm{O}_{4}-\mathrm{MW}-\mathrm{B},-\mathrm{HT}-\mathrm{B},-\mathrm{SG}$, and -PM samples and of reference compounds $\mathrm{Co}^{\mathrm{II}} \mathrm{O}$ and $\mathrm{LiCo}^{\mathrm{III}} \mathrm{O}_{2}$ (inset: satellite of the Co $2 \mathrm{p}_{3 / 2}$ peak); (b) Wagner plot using the Co $2 \mathrm{p}_{3 / 2}$ core-level binding energy and the Co L3VV Auger electron kinetic energy. References $\left(\mathrm{Co}_{3} \mathrm{O}_{4}{ }^{*}\right.$, $\mathrm{Co}^{*}$, and $\left.\mathrm{CoO}^{*}\right)$ were obtained from the NIST database. ${ }^{80}$

and the binding energies, the modified Auger parameters, is illustrated as diagonal lines. ${ }^{83}$ The Auger parameter is insensitive to charging and particularly useful when comparing spectra of insulating samples with results from the literature. Modified Auger parameters from the National Institute of Standards and Technology (NIST) are given as references $\left(\mathrm{Co}_{3} \mathrm{O}_{4}{ }^{*}, \mathrm{Co}^{*}\right.$, and $\left.\mathrm{CoO}^{*}\right)$ as indicated by the orange lines. ${ }^{80}$

The modified Auger parameters for the as-synthesized $\mathrm{Co}_{3} \mathrm{O}_{4}-\mathrm{MW}-\mathrm{B},-\mathrm{HT}-\mathrm{B}$, and PM samples are on the same line with the $\mathrm{Co}_{3} \mathrm{O}_{4}{ }^{*}$ reference. Interestingly, the measured $\mathrm{Co}^{\mathrm{II}} \mathrm{O}$ also coincides with this line, implying oxidation of the surface. The SG sample is closer to the $\mathrm{LiCo}^{\mathrm{III}} \mathrm{O}_{2}$ line, which is in good agreement with the absence of a strong satellite emission as shown in Figure 5a. These findings correlate well with the previous spectroscopic measurements, showing the same trends, namely, lower average oxidation states for samples synthesized at lower temperatures.

Water Oxidation Performance of $\mathrm{Co}_{3} \mathrm{O}_{4}$ Samples from Different Preparative Routes. The water oxidation performance of $\mathrm{Co}_{3} \mathrm{O}_{4}$ samples synthesized by nine different methods was tested using the three most widely applied approaches, namely, photocatalytic, chemical, and electrocatalytic oxidation. The results are summarized in Figure 6, and for a better assessment of the activity, the BET surface area and the mean-square disorder parameter $\sigma^{2}$ values are included as well. A version of Figure 6 with data normalized to the specific

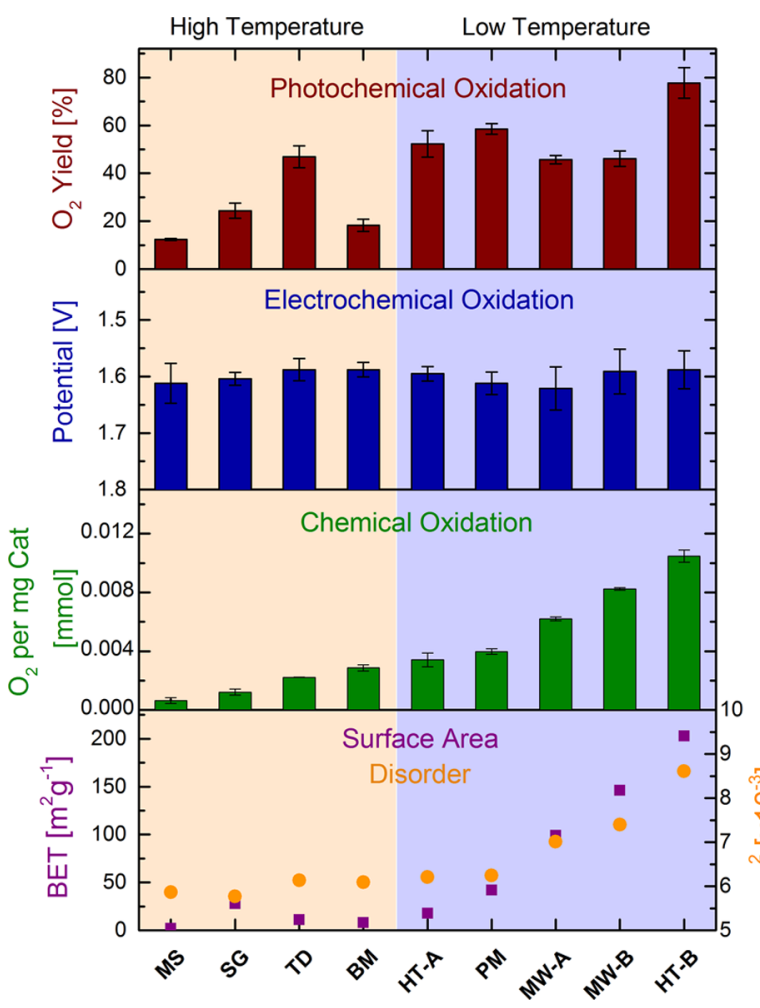

Figure 6. Comparison of the water oxidation activity of spinel $\mathrm{Co}_{3} \mathrm{O}_{4}$ synthesized with different methods by applying photochemical, electrochemical, and chemical oxidation methods, together with the respective BET surface area and the mean-square disorder parameter $\sigma^{2}$. For the photochemical oxidation, a standard $\left[\mathrm{Ru}(\mathrm{bpy})_{3}\right]^{2+} / \mathrm{S}_{2} \mathrm{O}_{8}{ }^{2-}$ protocol was used with a borate buffer $(\mathrm{pH} 8.5)$. Electrocatalytic activity is compared by the potentials vs reversible hydrogen electrode (RHE) at $1 \mathrm{~mA} / \mathrm{cm}^{2}$ in $1 \mathrm{M} \mathrm{KOH}$, and chemical oxidation was tested in $146 \mathrm{mM}$ cerium(IV) ammonium nitrate (CAN).

surface area can be found in the Supporting Information (SI) (Figure S6).

Photocatalytic Water Oxidation. For photocatalytic water oxidation, a standard $\left[\mathrm{Ru}(\text { bpy })_{3}\right]^{2+} / \mathrm{S}_{2} \mathrm{O}_{8}{ }^{2-} /$ light assay was used at $\mathrm{pH}$ 8.5. In this case, through visible-light excitation of $\left[\mathrm{Ru}(\mathrm{bpy})_{3}\right]^{2+}$ and subsequent oxidative quenching by persulfate, the one-electron oxidant $\left[\mathrm{Ru}(\mathrm{bpy})_{3}\right]^{3+}$ is generated in situ $\left[E^{\circ}=1.26 \mathrm{~V} \text { vs normal hydrogen electrode (NHE) }\right]^{84}$ Figure 6 shows a quite significant difference in activity. The samples synthesized at lower temperatures generally show higher OER activity, with the hydrothermally synthesized $\mathrm{Co}_{3} \mathrm{O}_{4}$-HT-B demonstrating the highest activity with an $\mathrm{O}_{2}$ yield of $77.7 \pm 6.4 \%$ at $203 \mathrm{~m}^{2} / \mathrm{g}$, compared with the samples obtained at high temperatures where the least active catalyst is $\mathrm{Co}_{3} \mathrm{O}_{4}$-MS with $12.4 \pm 0.4 \%$ at a surface area of only $2 \mathrm{~m}^{2} / \mathrm{g}$. This goes hand in hand with the observed high surface areas of MW-A $\left(99 \mathrm{~m}^{2} / \mathrm{g}\right)$, MW-B $\left(146 \mathrm{~m}^{2} / \mathrm{g}\right)$, and HT-B $\left(203 \mathrm{~m}^{2} / \mathrm{g}\right)$. However, HT-A and PM, which exhibit relatively low surface areas, also show higher performance than most of the samples. Among the high-temperature samples, $\mathrm{Co}_{3} \mathrm{O}_{4}-\mathrm{MS}$, - $\mathrm{BM}$, and -SG show a trend toward higher activity upon increasing surface area. $\mathrm{Co}_{3} \mathrm{O}_{4}-\mathrm{TD}$ is again an exception with a rather high activity of $46.9 \pm 4.6 \%$ for its comparably low surface area of $11 \mathrm{~m}^{2} / \mathrm{g}$. Note that the disorder among the samples follows a related trend related to the surface area. No clear correlation between the activity and either of the parameters surface area, disorder, or valence state can be seen in photocatalytic water 
oxidation. The general photocatalytic performance trend reveals a higher activity for materials synthesized through low-temperature hydrothermal or precipitation methods $\left(\leq 180{ }^{\circ} \mathrm{C}\right)$ than for materials synthesized at high temperatures $\left(\geq 400{ }^{\circ} \mathrm{C}\right)\left(\mathrm{Co}_{3} \mathrm{O}_{4}\right.$-TD being the above-mentioned exception). Consequently, the selected synthetic method exerts a clear effect on photocatalytic water oxidation activity.

Electrocatalytic Performance. Electrochemical measurements were performed in a three-electrode setup, using $\mathrm{Ag} /$ $\mathrm{AgCl}$ as the reference electrode and $\mathrm{Pt}$ as the counter electrode. $\mathrm{Ag} / \mathrm{AgCl}$ is still widely applied as the reference electrode for measurements in basic media (for example, $1 \mathrm{M}$ $\mathrm{KOH}$ ), when keeping in mind that minor stability issues can occur due to silver oxide formation in basic conditions. We performed control experiments using a $\mathrm{Ag} / \mathrm{AgCl}$ reference electrode to ensure that such effects did not affect the required accuracy of our measurements. ${ }^{85-87}$ Considering the recently shown instability of $\mathrm{Pt}$ under certain conditions, this occurs mainly in acidic environments and affects the water reduction half reaction rather than the oxygen evolution process. Further discussions can be found in the SI and in Figure S10a. ${ }^{88-92}$ To evaluate the electrocatalytic water oxidation performance, the spinel samples were coated on fluorine doped tin oxide (FTO), and cyclic voltammetry as well as chronoamperometry was performed, first stepwise from 0.45 to $0.65 \mathrm{~V}$ versus $\mathrm{Ag} / \mathrm{AgCl}$ and then for $2 \mathrm{~h}$ at $0.6 \mathrm{~V}$. The electrodes were investigated before and after these measurements with scanning electron microscopy imaging, Raman spectroscopy, and PXRD (Figures S8-S10). All of these characterizations did not show notable changes of the electrodes. Only in the PXRD patterns did the postcatalytic samples show increased intensity of the FTO peaks, which is most likely due to partial detachment of the catalyst from the electrode, but not arising from intrinsic changes of the catalyst itself. No clear trend is apparent from the cyclic voltammograms, where all samples showed an onset potential in the range of $1.49-1.64 \mathrm{~V}$ versus RHE with significant standard deviations of $0.03 \mathrm{~V}$ (see Figure S8). The only remarkable feature is that $\mathrm{Co}_{3} \mathrm{O}_{4}$-MS, with an overpotential of $1.64 \mathrm{~V}$ versus RHE, is outperformed clearly by all other materials. For a better internal comparison of the obtained materials, stepwise chronoamperometry was conducted to eliminate the diffusion current, therefore representing the catalytic activity more reliably. The potentials at $1 \mathrm{~mA} /$ $\mathrm{cm}^{2}$ are determined from Figure S11 and compared in Figure 6. Other than in photocatalytic tests, even from these more accurate measurements, no clear influence on the electrocatalytic performance is evident. All potentials at $1 \mathrm{~mA} / \mathrm{cm}^{2}$ are in the range of $1.57-1.62 \mathrm{~V}$ versus $\mathrm{RHE}$ with a comparatively large error of $0.024 \mathrm{~V}$. This indicates that the differences among the materials, such as in surface area, disorder, or oxidation state, are less important for electrocatalytic water oxidation, that is, the influence of the synthetic method is rather negligible here. As the postcatalytic investigations still show the presence of $\mathrm{Co}_{3} \mathrm{O}_{4}$ (see SI, pre- and postcatalytic analyses), the observed leveling may point to a reversible precatalytic formation of a thin shell of $\mathrm{CoO}_{x}(\mathrm{OH})_{y}$, in line with the in situ XRD/XAS study of Dau and Strasser et al. describing the reversible formation of a catalytically active subnanometer $\mathrm{CoO}_{x}(\mathrm{OH})_{y}$ layer containing di- $\mu$-oxo-bridged $\mathrm{Co}^{3+/ 4+}$ ions. ${ }^{31} \mathrm{~A}$ related in situ study by Chen et al. on $\mathrm{Co}_{3} \mathrm{O}_{4} @ \mathrm{CoO}$ nanocubes supported the intermediate formation of active $\alpha$ - and $\beta$-CoOOH thin layers. ${ }^{93}$ In light of these findings, pristine surface compositions and structures of such oxides would indeed be relativized to a large extent in electrochemical tests.

Chemical Oxidation Performance. Chemical water oxidation was tested with the strong one-electron oxidant cerium(IV) ammonium nitrate (CAN) with an $E^{\circ}$ of $1.7 \mathrm{~V}$ versus NHE. ${ }^{94,95} \mathrm{CAN}$-assisted oxidation is a relatively simple and straightforward protocol for WOC assessment since the kinetics are driven in one-electron steps and commercially available $\mathrm{O}_{2}$ sensors can be used. However, CAN is only sufficiently stable at low $\mathrm{pH}$ values of typically 0.9 , which limits its applicability. ${ }^{96}$ Even though chemical and photochemical water oxidation tests are thus performed at very different $\mathrm{pH}$ values, their "overpotentials" for water oxidation correspond to comparable $E^{\circ}$ at the given $\mathrm{pH}$ values. ${ }^{14}$ In our case, water oxidation was tested with a standard method, measuring $\mathrm{O}_{2}$ production by a luminescent dissolved oxygen (LDO) electrode with results between $5 \times 10^{-4}$ and $10^{-2} \mathrm{mmol}$ oxygen $/ \mathrm{mg}$ catalyst. $\mathrm{Co}_{3} \mathrm{O}_{4}$-HT-B was the most active catalyst $\left(1.05 \times 10^{-2} \mathrm{mmol}\right.$ oxygen $\left./ \mathrm{mg}\right)$, and $\mathrm{Co}_{3} \mathrm{O}_{4}$-MS showed the lowest activity $\left(6.45 \times 10^{-4} \mathrm{mmol}\right.$ oxygen $/ \mathrm{mg}$, see Figure 6$)$, as observed for photocatalytic oxidation. Despite this similarity and the comparable "overpotentials", the activities of the other cobalt oxides vary drastically between both test methods. In contrast to the photochemical oxidation, the activities for the chemical oxidation display the expected correlations with the material parameters. The activity increases clearly with the BET surface area. Likewise, the increasing disorder among the sample series results in continuously higher activity. As BET surface area and disorder show similar trends, both being linked to the preparative history, a reasonable further narrowing to one key performance parameter is not possible within the present data set. Additionally, the lower general oxidation states derived from XANES and XPS data, indicating excess $\mathrm{Co}^{2+}$ associated with oxygen vacancies, could be a key performance parameter. Generally, samples synthesized at lower temperatures show higher activities than the hightemperature samples, such as $\mathrm{Co}_{3} \mathrm{O}_{4}-\mathrm{MS}$, -BM, and -SG (Figure 6).

Trends in WOC Assessment. All in all, quite different performance trends were observed for $\mathrm{Co}_{3} \mathrm{O}_{4}$ WOCs when investigated with all three catalytic methods. This agrees with the first fundamental investigation along these lines by Stahl et al. ${ }^{14}$ comparing different manganese oxide types for photocatalytic, chemical, and electrocatalytic water oxidation as well as with subsequent studies of Ding et al. ${ }^{68}$ on doped iron-based oxides. The present study newly demonstrates that even the catalytic activity of a single material type can differ widely between test methods when it undergoes different preparative histories. While Antonietti and Driess et al. ${ }^{41}$ tailored the particle size of cobalt oxides with related synthetic methods and found the efficiency of photo- and electrocatalytic water oxidation of $\mathrm{Co}_{3} \mathrm{O}_{4}$ nanoparticles to depend on the available surface area, our previous studies on $\mathrm{Co}_{3} \mathrm{O}_{4}$ hydrothermal growth mechanisms indicated that the surface area is not by all means the decisive performance parameter. ${ }^{13}$

While photochemical and chemical oxidation are both molecular processes, they were found to respond differently to the involved material parameters, that is, the preparative method exerts a clear influence on the WOC activity. Surface area, oxidation state, and disorder were identified as the most important parameters for the chemical oxidation performance. In contrast, no such trend for these parameters could be found for the photochemical oxidation. However, in both test 
methods, $\mathrm{Co}_{3} \mathrm{O}_{4}$ samples synthesized at higher temperatures generally show lower activity than those obtained at notably lower synthesis temperatures. As for electrochemical water oxidation, no parameter dependence with respect to surface area, particle size, disorder, etc. emerged, so that the choice of the synthesis method exerted a negligible effect on the electrocatalytic performance.

\section{CONCLUSIONS}

In this work, a comprehensive three-step strategy using spineltype $\mathrm{Co}_{3} \mathrm{O}_{4}$ water oxidation catalysts (WOCs) as a model system was newly applied to investigate the complex parameter space of preparative history, material properties, and the resulting performance as a function of the applied catalytic driving force. To this end, nine different synthetic approaches to $\mathrm{Co}_{3} \mathrm{O}_{4}$ were first performed, covering a wide spectrum of low- and high-temperature methods. Next, key physical and surface properties of the as-synthesized products were compared, such as oxidation states, crystallinity, disorder, and particle size. Finally, this spectrum of cobalt oxide materials was compared with respect to their WOC activities in the three most widely applied test methods, namely, photocatalytic, electrocatalytic, and chemical water oxidation.

The $\mathrm{Co}_{3} \mathrm{O}_{4}$ samples synthesized at lower temperatures show higher disorder, as determined from EXAFS fitting and in line with Raman spectroscopy results. These more disordered samples also contain lower fractions of $\mathrm{Co}$ (III) than those exhibiting a higher degree of crystallinity, as evident from XPS and XANES data. Generally, cobalt oxides synthesized at low temperatures $\left(\leq 180^{\circ} \mathrm{C}\right)$ show higher water oxidation activities in chemical and photocatalytic tests than those obtained at higher temperatures. Chemical oxidation with CAN brought forward the clearest correlation between increasing catalytic activity and higher surface area/disorder along with lower average cobalt oxidation states. In contrast, the electrochemical water oxidation activity is quite insensitive to variations in the material properties. Surprisingly, no clear photocatalytic activity trends were observed for the $\mathrm{Co}_{3} \mathrm{O}_{4}$ sample spectrum.

All in all, we demonstrate that the preparative history exerts a crucial influence on the material properties of $\mathrm{Co}_{3} \mathrm{O}_{4}$ WOCs. These distinct synthesis-dependent properties give rise to significant activity differences in chemical and photochemical assays. Our systematic study shows that acquiring comprehensive synthetic insight is a fundamental prerequisite for any further properties-performance relationships. We here show their striking complexity for an apparently straightforward binary oxide system. In the long term, control over the entire parameter space of preparation, properties, and performance will require machine learning approaches to expedite the optimization of a wide spectrum of catalytic and other functional materials.

\section{EXPERIMENTAL SECTION AND METHODS}

Synthetic Procedures. Hydrothermal Synthesis (HT-A). For the hydrothermal synthesis of $\mathrm{Co}_{3} \mathrm{O}_{4},{ }^{56} 0.24 \mathrm{~g}$ of urea (4 $\mathrm{mmol})$ and $0.233 \mathrm{~g}$ of $\mathrm{Co}\left(\mathrm{NO}_{3}\right)_{2} \cdot 6 \mathrm{H}_{2} \mathrm{O}(0.82 \mathrm{mmol})$ were dissolved in $10 \mathrm{~mL}$ of $\mathrm{H}_{2} \mathrm{O}_{2}(30 \mathrm{wt} \%)$ solution under vigorous stirring. The homogeneous reaction solution was transferred to a $15 \mathrm{~mL}$ poly(tetrafluoroethylene) (PTFE)-lined stainless steel autoclave and heated to $150{ }^{\circ} \mathrm{C}\left(4.5 \mathrm{C}^{\circ} / \mathrm{min}\right)$. The holding temperature was maintained for $3 \mathrm{~h}$. The autoclaves were cooled down rapidly under cold running water $\left(10^{\circ} \mathrm{C}\right)$ for 8 min. The black precipitate was purified by centrifugation/ resuspension (5000 rpm, $8 \mathrm{~min}, 2 \times \mathrm{H}_{2} \mathrm{O}$ and $\left.2 \times \mathrm{EtOH}\right)$ and dried at $78{ }^{\circ} \mathrm{C}$ for $16 \mathrm{~h}$ in air.

Alternative Hydrothermal Synthesis (HT-B). The alternative hydrothermal synthesis was carried out according to the following procedure: ${ }^{97} 291 \mathrm{mg}$ of $\mathrm{Co}\left(\mathrm{NO}_{3}\right)_{2} \cdot 6 \mathrm{H}_{2} \mathrm{O}(1 \mathrm{mmol})$ and $42.5 \mathrm{mg}$ of $\mathrm{NaNO}_{3}(0.5 \mathrm{mmol})$ were dissolved in $15 \mathrm{~mL}$ of $\mathrm{H}_{2} \mathrm{O}$. After 10 min of stirring, $15 \mathrm{~mL}$ of $\mathrm{NH}_{3}(25 \%)$ solution was slowly added, and after 10 more minutes of stirring, 1.5 $\mathrm{mL}$ of $\mathrm{H}_{2} \mathrm{O}_{2}(30 \mathrm{wt} \%)$ solution was added. The reaction solution was transferred to a $15 \mathrm{~mL}$ PTFE-lined stainless steel autoclave and heated to $140{ }^{\circ} \mathrm{C}\left(4.5 \mathrm{C}^{\circ} / \mathrm{min}\right)$. The holding temperature was maintained for $6 \mathrm{~h}$ and then cooled to room temperature naturally. The black precipitate was purified by centrifugation/resuspension $\left(5000 \mathrm{rpm}, 8 \mathrm{~min}, 2 \times \mathrm{H}_{2} \mathrm{O}\right.$ and 2 $\times \mathrm{EtOH})$ and dried at $78{ }^{\circ} \mathrm{C}$ for $16 \mathrm{~h}$ in air.

Microwave Hydrothermal Synthesis (MW-A). For the microwave hydrothermal synthesis of $\mathrm{Co}_{3} \mathrm{O}_{4}, 1.8 \mathrm{mmol}$ of $\mathrm{Co}\left(\mathrm{NO}_{3}\right)_{2} \cdot 6 \mathrm{H}_{2} \mathrm{O}$ was dissolved in $15 \mathrm{~mL}$ of $\mathrm{H}_{2} \mathrm{O}$ and the $\mathrm{pH}$ was adjusted to 11 with $\mathrm{NH}_{3}(25 \%)$ solution. The resulting dispersion was filled into a $50 \mathrm{~mL}$ Teflon liner, which was closed and fixed inside a frame before introducing into the microwave. Reactions were carried out in a MARS5 microwave (CEM Corporation). The synthesis was conducted by controlling the temperature: $30 \mathrm{~min}$ ramping to $180{ }^{\circ} \mathrm{C}$ and then holding this temperature for $60 \mathrm{~min}$ under constant stirring. The temperature and pressure were measured from the reference vessel, which was equipped with appropriate sensors. After letting the dispersions cool down to room temperature, the product was separated by centrifugation and washed with $\mathrm{H}_{2} \mathrm{O}$.

Microwave Alternative Hydrothermal Synthesis (MW-B). First, $100 \mathrm{mM} \mathrm{Co}\left(\mathrm{NO}_{3}\right)_{2} \cdot 6 \mathrm{H}_{2} \mathrm{O}$ and $50 \mathrm{mM} \mathrm{NaNO}{ }_{3}$ were dissolved in $5 \mathrm{~mL}$ of $\mathrm{H}_{2} \mathrm{O}$. Then, $5 \mathrm{~mL}$ of $\mathrm{NH}_{3}(25 \%)$ solution and $0.5 \mathrm{~mL}$ of $\mathrm{H}_{2} \mathrm{O}_{2}$ (32 wt \%) were added before sealing the solution in the corresponding vessels as described in the above section. The reaction was carried out at $140{ }^{\circ} \mathrm{C}$ for $1 \mathrm{~h}$ after 30 min of ramping time.

Mild Oxidative Synthesis/Precipitation Method (PM). The nitrate-salt-mediated precipitation method was carried out according to a previously reported procedure. ${ }^{55} \mathrm{NaNO}_{3}(15 \mathrm{~g}$, $176 \mathrm{mmol}$ ) was added to a $50 \mathrm{~mL}$ two-necked round-bottom flask, equipped with a water-cooled reflux condenser containing $25 \mathrm{~mL}$ of $\mathrm{NaOH}$ solution $(0.3 \mathrm{M})$. The reaction mixture was heated to $95{ }^{\circ} \mathrm{C}$, and an aqueous solution of $\mathrm{Co}\left(\mathrm{NO}_{3}\right)_{2}(5.0 \mathrm{~mL}, 1.0 \mathrm{M})$ was added within $1 \mathrm{~min}$, which led to instantaneous precipitation. Throughout the precipitation and aging period, the reaction mixture was stirred vigorously and purged with air while keeping the temperature constant at $95^{\circ} \mathrm{C}$ for $16 \mathrm{~h}$. Afterward, the suspension was cooled to room temperature naturally under ambient conditions. The black precipitate was purified by centrifugation/resuspension $(5000$ rpm, $8 \mathrm{~min}, 2 \times \mathrm{HCl}(2 \mathrm{M}), 1 \times \mathrm{H}_{2} \mathrm{O}$ and $\left.1 \times \mathrm{EtOH}\right)$ and dried at $78{ }^{\circ} \mathrm{C}$ for $16 \mathrm{~h}$ in air.

Thermal Decomposition (TD). For the synthesis of $\mathrm{Co}_{3} \mathrm{O}_{4}$ through thermal decomposition, $\mathrm{Co}\left(\mathrm{NO}_{3}\right)_{2} \cdot 6 \mathrm{H}_{2} \mathrm{O}$ was added to a crucible, heated in a muffle furnace to $450{ }^{\circ} \mathrm{C}\left(4.5{ }^{\circ} \mathrm{C} /\right.$ $\mathrm{min}$ ), and kept at this temperature for $3 \mathrm{~h}$. Afterward, the product was cooled to room temperature naturally.

Ball Milling (BM) and Thermal Decomposition. Co$\left(\mathrm{NO}_{3}\right)_{2} \cdot 6 \mathrm{H}_{2} \mathrm{O}$ was ground in a planetary ball mill (Retsch) at a speed of $500 \mathrm{rpm}$ for $2 \mathrm{~h}$. The ball-milled powder was 
calcined in air at $450{ }^{\circ} \mathrm{C}$ for $1 \mathrm{~h}$ to obtain larger $\mathrm{Co}_{3} \mathrm{O}_{4}$ nanoparticles.

Sol-Gel (SG). A variation of the sol-gel method from ref 98 was applied: $1.8 \mathrm{mmol} \mathrm{Co}\left(\mathrm{NO}_{3}\right)_{2} \cdot 6 \mathrm{H}_{2} \mathrm{O}$ and $2.7 \mathrm{mmol}$ citric acid were dissolved in $25 \mathrm{~mL}$ of $\mathrm{H}_{2} \mathrm{O}$. The solution was heated up slowly while stirring until a gel was formed. It was heated up to $400{ }^{\circ} \mathrm{C}$ for $1 \mathrm{~h}$, transferred into a ceramic crucible, and then heated again to $700{ }^{\circ} \mathrm{C}$ for $10 \mathrm{~h}$, yielding $\mathrm{Co}_{3} \mathrm{O}_{4}$.

Molten Salt (MS) Method. $\mathrm{Co}\left(\mathrm{NO}_{3}\right)_{2} \cdot 6 \mathrm{H}_{2} \mathrm{O}(0.291 \mathrm{~g}, 1$ mmol) was mixed with $\mathrm{LiNO}_{3}(6.895 \mathrm{~g}, 100 \mathrm{mmol})$, ground, and transferred to an alumina crucible. The crucible was put into a muffle furnace, heated to $400{ }^{\circ} \mathrm{C}\left(12.6{ }^{\circ} \mathrm{C} / \mathrm{min}\right)$, and kept at this temperature for $30 \mathrm{~min}$. Afterward, the mixture cooled down to room temperature naturally and was washed $\left(2 \times \mathrm{H}_{2} \mathrm{O}\right.$ and $\left.1 \times \mathrm{EtOH}\right)$ and dried at $78{ }^{\circ} \mathrm{C}$ for $16 \mathrm{~h}$ in air. ${ }^{50}$

Catalytic Measurements. Photocatalytic Tests. Photocatalytic water oxidation tests were performed using a standard $\left[\mathrm{Ru}(\text { bpy })_{3}\right]^{2+} / \mathrm{S}_{2} \mathrm{O}_{8}{ }^{2-}$ protocol. ${ }^{13}$ Photocatalytic reaction suspensions were handled in a dark environment while being shielded from light. According to the protocol, $\mathrm{Co}_{3} \mathrm{O}_{4}$ photocatalyst $(2.00 \mathrm{mg}, 8.3 \mathrm{mmol}), \mathrm{Na}_{2} \mathrm{~S}_{2} \mathrm{O}_{8}$ sacrificial electron acceptor $(9.5 \mathrm{mg}, 5 \mathrm{mM})$, and $\left[\mathrm{Ru}(\mathrm{bpy})_{3}\right] \mathrm{Cl}_{2} \cdot 6 \mathrm{H}_{2} \mathrm{O}$ photosensitizer $(6.0 \mathrm{mg}, 1 \mathrm{mM})$ were mixed with borate buffer $(8 \mathrm{~mL}, 80 \mathrm{mM}, \mathrm{pH} 8.5)$ in a $10 \mathrm{~mL}$ headspace glass vial. The glass vial was subsequently sealed gastight with a rubber septum (PTFE) and an aluminum crimp cap and sonicated for $3 \mathrm{~min}$. To remove all of the oxygen before starting the test, the suspension was degassed through purging with helium (purity 5.0) for $10 \mathrm{~min}$. Afterward, the catalytic suspension was illuminated with a $460 \mathrm{~nm}$ high flux light-emitting diode light (26.1 mW/cm, Rhopoint Components Ltd.) under constant stirring $(1200 \mathrm{rpm})$ for $25 \mathrm{~min}$. For evaluating the amount of evolved oxygen, a $100 \mu \mathrm{L}$ gas sample was taken from the headspace with a gastight microliter syringe (Hamilton$1825 \mathrm{RN}$ ) and injected into the gas chromatograph (GC). A previously determined linear GC calibration curve was used to quantify the oxygen evolution (air contamination was corrected). The error of $\mathrm{O}_{2}$ yield was determined by the standard deviation of minimum three photocatalytic tests for each sample.

Chemical Water Oxidation. The standard CAN method was used to evaluate the chemical water oxidation activity of the catalysts. ${ }^{15}$ With a standard potential of about $1.7 \mathrm{~V}$ versus $\mathrm{NHE}, \mathrm{CAN}$ is a suitable one-electron oxidant to promote the water oxidation. CAN ( $2 \mathrm{~g}$ ) was dissolved in Milli-Q water (40 $\mathrm{mL}$ ), and the solution was degassed with argon. The respective catalysts ( $2 \mathrm{mg}$ each) were added, and the oxygen evolution was recorded by a luminescent dissolved oxygen (LDO) sensor in the stirred solution for about $45 \mathrm{~min}$. The highest obtained value was used for the evaluation. A Hach HQ40D multimeter with an LDO 101 sensor was used for oxygen determination.

Electrocatalytic Tests. Electrocatalytic measurements were carried out in $1 \mathrm{M} \mathrm{KOH}$, using a $\mathrm{Ag} / \mathrm{AgCl}$ reference electrode and a Pt counter electrode. First, cyclic voltammetry cycles from 0 to $0.7 \mathrm{~V}$ versus reference with $0.005 \mathrm{mV}$ step size were measured, prior to conducting chronoamperometry. For comparison, only the second cycle was considered upon data evaluation. The potential was stepwise increased starting from 0.45 to $0.65 \mathrm{~V}$ in $0.01 \mathrm{~V}$ steps and held for $5 \mathrm{~min}$ each to eliminate diffusion currents. The stabilized current after $5 \mathrm{~min}$ was used for further evaluation. After the steps, a potential of $0.6 \mathrm{~V}$ versus the reference electrode was applied for $2 \mathrm{~h}$ for stability tests. Electrochemical measurements were carried out with a Bio-Logic SAS SP-150 Potentiostat. As the reference electrode, an Aldrich glass reference electrode $\mathrm{Ag} / \mathrm{AgCl}$ with 3 $\mathrm{M} \mathrm{KCl}$ and as the counter electrode, a $\mathrm{Pt}$ foil were used. The working electrodes were produced by dispersing $2 \mathrm{mg}$ of the catalyst in $100 \mu \mathrm{L}$ of $\mathrm{H}_{2} \mathrm{O}$, applying $40 \mu \mathrm{L}$ of this dispersion on $1 \mathrm{~cm}^{2}$ FTO, and drying the electrodes at $80{ }^{\circ} \mathrm{C}$ for $30 \mathrm{~min}$ before covering with $10 \mu \mathrm{L}$ of Nafion $1 \%$ solution.

Materials and Methods. Ultrapure $\mathrm{H}_{2} \mathrm{O}(18.2 \mathrm{M} \Omega$ ) was generally used for synthesis (Merck, Milli-Q Type 1 Ultrapure Water Systems). All chemicals and solvents were purchased from commercial suppliers: $\mathrm{CoO}$ (Aldrich, $\geq 99.99 \%$ metals basis), $\mathrm{LiCoO}_{2}$ (Alfa Aesar, 99.5\% metals basis), $\mathrm{Co}\left(\mathrm{NO}_{3}\right)_{2}$. $6 \mathrm{H}_{2} \mathrm{O}$ (Sigma-Aldrich, $99.999 \%$ trace metal basis), [Ru(bpy) $\left.{ }_{3}\right] \mathrm{Cl}_{2} \cdot 6 \mathrm{H}_{2} \mathrm{O}$ (Sigma-Aldrich, 99.95\%), $\mathrm{Na}_{2} \mathrm{~S}_{2} \mathrm{O}_{8}$ (SigmaAldrich, 99.0\%), $\mathrm{H}_{2} \mathrm{O}_{2} 30$ wt \% in $\mathrm{H}_{2} \mathrm{O}$ (Sigma-Aldrich, ACS Reagent), urea (Sigma-Aldrich, 98\%), $\mathrm{NaNO}_{3}$ (Sigma-Aldrich, $\geq 99.0 \%$ ), $\mathrm{NaOH}$ (Acros Organics, 97+\%), $\mathrm{LiNO}_{3}$ (SigmaAldrich, ReagentPlus), ammonia solution 25\% (Merck, for analysis), ethanol (VWR Chemicals, absolute), citric acid (Merck, anhydrous for synthesis), KOH (Honeywell, pellets, extra pure), $\mathrm{HCl}$ (Fluka Analytical), Nafion perfluorinated resin solution 5 wt \% in a mixture of lower aliphatic alcohols, and water (Sigma-Aldrich).

Powder X-ray diffraction (PXRD) patterns were recorded with a STOE STADI P diffractometer in the transmission mode (flat-plate sample holder, Ge monochromator, and Mo $\mathrm{K}_{\alpha 1}$ radiation) using a position-sensitive microstrip solid-state detector (MYTHEN 1K). Raman spectroscopy was performed with a Renishaw inVia Qontor confocal Raman microscope equipped with a diode laser $(785 \mathrm{~nm})$. Gas chromatography (GC) measurements were recorded with Agilent Technologies 7820 A equipped with a thermal conductivity detector and a 30 $\mathrm{m} \times 0.53 \mathrm{~mm}$ packed HP molecular sieve column with a 50.0 $\mu \mathrm{m}$ film and He carrier gas (purity 6.0). Nitrogen sorption isotherms were recorded with a Quantachrome Quadrasorb SI porosimeter at $77 \mathrm{~K}$ after degassing at $100{ }^{\circ} \mathrm{C}$ for $20 \mathrm{~h}$ under vacuum. The Brunauer-Emmet-Teller (BET) model was applied for adsorption branch points $\left(0.05>p / p_{0}<0.3\right)$ to calculate the apparent surface area. Transmission electron microscopy (TEM) images were taken with JEOL JEM-1400 Plus equipped with a JEOL CCD camera Ruby (8 M pixel) and $\mathrm{a} \mathrm{LaB}_{6}$ crystal as an emitter $(120 \mathrm{kV})$. X-ray absorption spectroscopy XANES and EXAFS at the Co $\mathrm{K}$ edge on solid powder samples dispersed in cellulose of the synthesized $\mathrm{Co}_{3} \mathrm{O}_{4}$ oxides and reference samples $\mathrm{Co}^{\mathrm{II}} \mathrm{O}, \mathrm{LiCo}^{\mathrm{III}} \mathrm{O}_{2}$ was carried out at the European Synchrotron Radiation Facility, Swiss-Norwegian Beamline BM31, Grenoble-France. The storage ring was run in the top-up mode (average current 40 $\mathrm{mA}$ ). The X-ray beam was collimated using a Si-coated mirror, and energy was scanned using a double crystal $\mathrm{Si}[111]$ monochromator. Measurements were performed at room temperature using a three-ionization chamber configuration in the transmission mode using a 13-element Ge detector. For energy calibrations, spectra of a metal Co foil were measured simultaneously at the second ionization chamber. The measured EXAFS spectra $k^{3} \chi(k)$ were extracted by data reduction, absorption edge energy calibration, and background subtraction as implemented in ATHENA. ${ }^{99}$ The spectra were reduced in the range $\Delta k \approx 3-14 \AA^{-1}$ and Fourier-transform to $\mathrm{FT}\left|k^{3} \chi(k)\right|$ into the real-space interval of $\Delta R \approx 0-6 \AA$. To calculate main values for interatomic distances, coordination numbers, and Debye-Waller factors $\sigma^{2}$ nonlinear least-squares fitting of the experimental $\mathrm{FT}^{3} k^{3} \chi(k) \mid$ spectra was carried out 
by ARTEMIS ${ }^{99}$ using atomic clusters of $\mathrm{Co}_{3} \mathrm{O}_{4}$ (ICSD code 27498), generated by $\mathrm{ATOMS}^{99}$ as implemented in IFEFFIT. $^{99}$ The amplitude and phase shifts for single and multiple scattering paths were calculated using FEFF6. ${ }^{100} \mathrm{X}$ ray photoelectron spectroscopy (XPS) was conducted using a Physical Electronics (PHI) Quantum 2000 spectrometer featuring monochromatic $\mathrm{Al} \mathrm{K}$ radiation, generated from an electron beam operated at $15 \mathrm{kV}$ and $35.8 \mathrm{~W}$. The energy scale of the instrument was calibrated using $\mathrm{Au}$ and $\mathrm{Cu}$ reference samples. The analysis was conducted at $1 \mathrm{e}^{-8} \mathrm{mbar}$, with an electron take-off angle of $45^{\circ}$ and a pass energy of $23.5 \mathrm{eV}$ for all samples. Charge compensation during the measurement was achieved using a low-energy electron source. The acquired spectra were then aligned using the main $(\mathrm{C}-\mathrm{C})$ component of the $\mathrm{C} 1 \mathrm{~s}$ core-level emission. The modified Auger parameter was calculated by adding the kinetic energy of the Co L3VV and Co $2 p_{3 / 2}$ binding energies.

\section{ASSOCIATED CONTENT}

\section{S Supporting Information}

The Supporting Information is available free of charge on the ACS Publications website at DOI: 10.1021/acsomega.9b01677.

Additional characterization and catalytic water oxidation measurements of the as-synthesized $\mathrm{Co}_{3} \mathrm{O}_{4}$ materials (PDF)

\section{AUTHOR INFORMATION}

\section{Corresponding Author}

*E-mail: greta.patzke@chem.uzh.ch.

\section{ORCID}

Lukas Reith: 0000-0003-4874-1476

Karla Lienau: 0000-0003-2067-6449

C. A. Triana: 0000-0003-1270-0410

Sebastian Siol: 0000-0002-0907-6525

Greta R. Patzke: 0000-0003-4616-7183

\section{Author Contributions}

L.R. and K.L. contributed equally to this work. The manuscript was written through contributions of all authors. All authors have given approval to the final version of the manuscript.

\section{Notes}

The authors declare no competing financial interest.

\section{ACKNOWLEDGMENTS}

The authors thank the University of Zurich and the UZH Research Priority Program Solar Light to Chemical Energy Conversion (URPP Light ChEC) for financial support. G.R.P. is grateful to the Swiss National Science Foundation (Sinergia Grant No. CRSII2_160801/1) for financial support. S.S. acknowledges funding from COST project IZCNZ0-174856 C16.0075, in the COST Action MP1407 (e-MINDS). All microscopy work was carried out at the Scientific Center for Optical and Electron Microscopy (ScopeM) at ETH Zurich. The authors thank S. Esmael Balaghi and Wenchao Wan (Department of Chemistry, UZH) for performing the XAS experiments.

\section{REFERENCES}

(1) Du, P.; Eisenberg, R. Catalysts made of earth-abundant elements $(\mathrm{Co}, \mathrm{Ni}, \mathrm{Fe})$ for water splitting: Recent progress and future challenges. Energy Environ. Sci. 2012, 5, 6012.
(2) Montoya, J. H.; Seitz, L. C.; Chakthranont, P.; Vojvodic, A.; Jaramillo, T. F.; Nørskov, J. K. Materials for solar fuels and chemicals. Nat. Mater. 2017, 16, 70-81.

(3) Chen, S.; Takata, T.; Domen, K. Particulate photocatalysts for overall water splitting. Nat. Rev. Mater. 2017, 2, No. 17050.

(4) Đokić, M.; Soo, H. S. Artificial photosynthesis by light absorption, charge separation, and multielectron catalysis. Chem. Commun. 2018, 54, 6554-6572.

(5) Kubicek, M.; Bork, A. H.; Rupp, J. L. M. Perovskite oxides - a review on a versatile material class for solar-to-fuel conversion processes. J. Mater. Chem. A 2017, 5, 11983-12000.

(6) Li, J.; Güttinger, R.; Moré, R.; Song, F.; Wan, W.; Patzke, G. R. Frontiers of water oxidation: the quest for true catalysts. Chem. Soc. Rev. 2017, 46, 6124-6147.

(7) Hunter, B. M.; Gray, H. B.; Müller, A. M. Earth-Abundant Heterogeneous Water Oxidation Catalysts. Chem. Rev. 2016, 116, 14120-14136.

(8) Najafpour, M. M.; Renger, G.; Hołyńska, M.; Moghaddam, A. N.; Aro, E.-M.; Carpentier, R.; Nishihara, H.; Eaton-Rye, J. J.; Shen, J.-R.; Allakhverdiev, S. I. Manganese Compounds as Water-Oxidizing Catalysts: From the Natural Water-Oxidizing Complex to Nanosized Manganese Oxide Structures. Chem. Rev. 2016, 116, 2886-2936.

(9) Özer, E.; Pawolek, Z.; Kühl, S.; Nong, H.; Paul, B.; Selve, S.; Spöri, C.; Bernitzky, C.; Strasser, P. Metallic Iridium Thin-Films as Model Catalysts for the Electrochemical Oxygen Evolution Reaction (OER) - Morphology and Activity. Surfaces 2018, 1, 151-164.

(10) Najafpour, M. M.; Kaboudin, B.; Mostafalu, R.; Shahbazy, M.; Safdari, R.; Kompany-Zareh, M. A proposed mechanism to form nanosized $\mathrm{Mn}$ oxides from the decomposition of $\beta$-cyclodextrin-Mn complex: Toward nanosized water-splitting catalysts with special morphology. Int. J. Hydrogen Energy 2017, 42, 11187-11198.

(11) Musić, S.; Popović, S.; Maljković, M.; Dragčević, Đ. Influence of synthesis procedure on the formation and properties of zinc oxide. J. Alloys Compd. 2002, 347, 324-332.

(12) Xing, Y.; Rosner, D. E. Prediction of Spherule Size in Gas Phase Nanoparticle Synthesis. J. Nanopart. Res. 1999, 1, 277-291.

(13) Reith, L.; Lienau, K.; Cook, D. S.; Moré, R.; Walton, R. I.; Patzke, G. R. Monitoring the Hydrothermal Growth of Cobalt Spinel Water Oxidation Catalysts: From Preparative History to Catalytic Activity. Chem. - Eur. J. 2018, 24, 18424-18435.

(14) Pokhrel, R.; Goetz, M. K.; Shaner, S. E.; Wu, X.; Stahl, S. S. The "Best Catalyst" for Water Oxidation Depends on the Oxidation Method Employed: A Case Study of Manganese Oxides. J. Am. Chem. Soc. 2015, 137, 8384-8387.

(15) Parent, A. R.; Crabtree, R. H.; Brudvig, G. W. Comparison of primary oxidants for water-oxidation catalysis. Chem. Soc. Rev. 2013, 42, 2247-2252.

(16) Singh, A.; Spiccia, L. Water oxidation catalysts based on abundant 1st row transition metals. Coord. Chem. Rev. 2013, 257, 2607-2622.

(17) Min, K.; Choi, B.; Park, K.; Cho, E. Machine learning assisted optimization of electrochemical properties for Ni-rich cathode materials. Sci. Rep. 2018, 8, No. 15778.

(18) Balachandran, P. V.; Kowalski, B.; Sehirlioglu, A.; Lookman, T. Experimental search for high-temperature ferroelectric perovskites guided by two-step machine learning. Nat. Commun. 2018, 9, No. 1668.

(19) Wang, J.; Cui, W.; Liu, Q.; Xing, Z.; Asiri, A. M.; Sun, X. Recent Progress in Cobalt-Based Heterogeneous Catalysts for Electrochemical Water Splitting. Adv. Mater. 2016, 28, 215-230.

(20) Artero, V.; Chavarot-Kerlidou, M.; Fontecave, M. Splitting water with cobalt. Angew. Chem., Int. Ed. 2011, 50, 7238-7266.

(21) Zhao, Q.; Yan, Z.; Chen, C.; Chen, J. Spinels: Controlled Preparation, Oxygen Reduction/Evolution Reaction Application, and Beyond. Chem. Rev. 2017, 117, 10121-10211.

(22) Wang, D.; Yu, Y.; He, H.; Wang, J.; Zhou, W.; Abruña, H. D. Template-free synthesis of hollow-structured $\mathrm{Co}_{3} \mathrm{O}_{4}$ nanoparticles as high-performance anodes for lithium-ion batteries. ACS Nano 2015, 9, $1775-1781$ 
(23) Luo, Y.; Kong, D.; Luo, J.; Wang, Y.; Zhang, D.; Qiu, K.; Cheng, C.; Li, C. M.; Yu, T. Seed-assisted synthesis of $\mathrm{Co}_{3} \mathrm{O}_{4} @ \alpha-$ $\mathrm{Fe}_{2} \mathrm{O}_{3}$ core-shell nanoneedle arrays for lithium-ion battery anode with high capacity. RSC Adv. 2014, 4, 13241.

(24) Gao, R.; Yang, Z.; Zheng, L.; Gu, L.; Liu, L.; Lee, Y.; Hu, Z.; $\mathrm{Liu}, \mathrm{X}$. Enhancing the Catalytic Activity of $\mathrm{Co}_{3} \mathrm{O}_{4}$ for $\mathrm{Li}-\mathrm{O}_{2}$ Batteries through the Synergy of Surface/Interface/Doping Engineering. ACS Catal. 2018, 8, 1955-1963.

(25) Li, W. Y.; Xu, L. N.; Chen, J. $\mathrm{Co}_{3} \mathrm{O}_{4}$ Nanomaterials in LithiumIon Batteries and Gas Sensors. Adv. Funct. Mater. 2005, 15, 851-857.

(26) Wang, R. M.; Liu, C. M.; Zhang, H. Z.; Chen, C. P.; Guo, L.; $\mathrm{Xu}$, H. B.; Yang, S. H. Porous nanotubes of $\mathrm{Co}_{3} \mathrm{O}_{4}$ : Synthesis, characterization, and magnetic properties. Appl. Phys. Lett. 2004, 85, 2080-2082.

(27) Zhou, M.; Cai, L.; Bajdich, M.; García-Melchor, M.; Li, H.; He, J.; Wilcox, J.; Wu, W.; Vojvodic, A.; Zheng, X. Enhancing Catalytic $\mathrm{CO}$ Oxidation over $\mathrm{Co}_{3} \mathrm{O}_{4}$ Nanowires by Substituting $\mathrm{Co}^{2+}$ with $\mathrm{Cu}^{2+}$. ACS Catal. 2015, 5, 4485-4491.

(28) Iosub, A. V.; Stahl, S. S. Catalytic Aerobic Dehydrogenation of Nitrogen Heterocycles Using Heterogeneous Cobalt Oxide Supported on Nitrogen-Doped Carbon. Org. Lett. 2015, 17, 4404-4407.

(29) Zhou, X.; Liu, Z.; Wang, Y.; Ding, Y. Facet effect of $\mathrm{Co}_{3} \mathrm{O}_{4}$ nanocrystals on visible-light driven water oxidation. Appl. Catal., $B$ 2018, 237, 74-84.

(30) Chua, C. S.; Ansovini, D.; Lee, C. J. J.; Teng, Y. T.; Ong, L. T.; Chi, D.; Hor, T. S. A.; Raja, R.; Lim, Y.-F. The effect of crystallinity on photocatalytic performance of $\mathrm{Co}_{3} \mathrm{O}_{4}$ water-splitting cocatalysts. Phys. Chem. Chem. Phys. 2016, 18, 5172-5178.

(31) Bergmann, A.; Martinez-Moreno, E.; Teschner, D.; Chernev, P.; Gliech, M.; de Araújo, J. F.; Reier, T.; Dau, H.; Strasser, P. Reversible amorphization and the catalytically active state of crystalline $\mathrm{Co}_{3} \mathrm{O}_{4}$ during oxygen evolution. Nat. Commun. 2015, 6, No. 8625 .

(32) Wang, H.-Y.; Hung, S.-F.; Chen, H.-Y.; Chan, T.-S.; Chen, H. M.; Liu, B. In Operando Identification of Geometrical-Site-Dependent Water Oxidation Activity of Spinel $\mathrm{Co}_{3} \mathrm{O}_{4}$. J. Am. Chem. Soc. 2016, $138,36-39$.

(33) Cordeiro, P. V. O.; Carvalho, N. M. F. Water Oxidation Reaction Catalyzed by $\mathrm{Co}_{3} \mathrm{O}_{4}$ Treated with Organic Compounds. Ind. Eng. Chem. Res. 2018, 57, 11259-11264.

(34) Zhang, G.; Yang, J.; Wang, H.; Chen, H.; Yang, J.; Pan, F. $\mathrm{Co}_{3} \mathrm{O}_{4-\delta}$ Quantum Dots As a Highly Efficient Oxygen Evolution Reaction Catalyst for Water Splitting. ACS Appl. Mater. Interfaces 2017, 9, 16159-16167.

(35) Zhang, N.; Shi, J.; Mao, S. S.; Guo, L. $\mathrm{Co}_{3} \mathrm{O}_{4}$ quantum dots: reverse micelle synthesis and visible-light-driven photocatalytic overall water splitting. Chem. Commun. 2014, 50, 2002-2004.

(36) Wei, R.; Fang, M.; Dong, G.; Lan, C.; Shu, L.; Zhang, H.; Bu, X.; Ho, J. C. High-Index Faceted Porous $\mathrm{Co}_{3} \mathrm{O}_{4}$ Nanosheets with Oxygen Vacancies for Highly Efficient Water Oxidation. ACS Appl. Mater. Interfaces 2018, 10, 7079-7086.

(37) Zhang, M.; de Respinis, M.; Frei, H. Time-resolved observations of water oxidation intermediates on a cobalt oxide nanoparticle catalyst. Nat. Chem. 2014, 6, 362-367.

(38) Rosen, J.; Hutchings, G. S.; Jiao, F. Synthesis, structure, and photocatalytic properties of ordered mesoporous metal-doped $\mathrm{Co}_{3} \mathrm{O}_{4}$. J. Catal. 2014, 310, 2-9.

(39) Liu, Q.; Chen, Z.; Yan, Z.; Wang, Y.; Wang, E.; Wang, S.; Wang, S.; Sun, G. Crystal-Plane-Dependent Activity of Spinel $\mathrm{Co}_{3} \mathrm{O}_{4}$ Towards Water Splitting and the Oxygen Reduction Reaction. ChemElectroChem 2018, 5, 1080-1086.

(40) Zhou, J.; Li, J.; Zhang, L.; Song, S.; Wang, Y.; Lin, X.; Gu, S.; Wu, X.; Weng, T.-C.; Wang, J.; Zhang, S. Highly Active Surface Structure in Nanosized Spinel Cobalt-Based Oxides for Electrocatalytic Water Splitting. J. Phys. Chem. C 2018, 122, 14447-14458.

(41) Grzelczak, M.; Zhang, J.; Pfrommer, J.; Hartmann, J.; Driess, M.; Antonietti, M.; Wang, X. Electro- and Photochemical Water Oxidation on Ligand-free $\mathrm{Co}_{3} \mathrm{O}_{4}$ Nanoparticles with Tunable Sizes. ACS Catal. 2013, 3, 383-388.
(42) Schenk, A. S.; Eiben, S.; Goll, M.; Reith, L.; Kulak, A. N.; Meldrum, F. C.; Jeske, H.; Wege, C.; Ludwigs, S. Virus-directed formation of electrocatalytically active nanoparticle-based $\mathrm{Co}_{3} \mathrm{O}_{4}$ tubes. Nanoscale 2017, 9, 6334-6345.

(43) Zhang, N.; Wang, Y.; Hao, Y.-C.; Ni, Y.-M.; Su, X.; Yin, A.-X.; $\mathrm{Hu}, \mathrm{C}$.-W. Ultrathin cobalt oxide nanostructures with morphologydependent electrocatalytic oxygen evolution activity. Nanoscale 2018, 10, 20313-20320.

(44) Xu, L.; Jiang, Q.; Xiao, Z.; Li, X.; Huo, J.; Wang, S.; Dai, L. Plasma-Engraved $\mathrm{Co}_{3} \mathrm{O}_{4}$ Nanosheets with Oxygen Vacancies and High Surface Area for the Oxygen Evolution Reaction. Angew. Chem., Int. Ed. 2016, 55, 5277-5281.

(45) Zhang, R.; Zhang, Y.-C.; Pan, L.; Shen, G.-Q.; Mahmood, N.; Ma, Y.-H.; Shi, Y.; Jia, W.; Wang, L.; Zhang, X.; Xu, W.; Zou, J.-J. Engineering Cobalt Defects in Cobalt Oxide for Highly Efficient Electrocatalytic Oxygen Evolution. ACS Catal. 2018, 8, 3803-3811.

(46) Bao, J.; Zhang, X.; Fan, B.; Zhang, J.; Zhou, M.; Yang, W.; Hu, X.; Wang, H.; Pan, B.; Xie, Y. Ultrathin Spinel-Structured Nanosheets Rich in Oxygen Deficiencies for Enhanced Electrocatalytic Water Oxidation. Angew. Chem., Int. Ed. 2015, 54, 7399-7404.

(47) Yang, N.; Shi, Y.; Schweiger, S.; Strelcov, E.; Belianinov, A.; Foglietti, V.; Orgiani, P.; Balestrino, G.; Kalinin, S. V.; Rupp, J. L. M.; Aruta, C. Role of Associated Defects in Oxygen Ion Conduction and Surface Exchange Reaction for Epitaxial Samaria-Doped Ceria Thin Films as Catalytic Coatings. ACS Appl. Mater. Interfaces 2016, 8, 14613-14621.

(48) Nong, H. N.; Reier, T.; Oh, H.-S.; Gliech, M.; Paciok, P.; Vu, T. H. T.; Teschner, D.; Heggen, M.; Petkov, V.; Schlögl, R.; Jones, T.; Strasser, P. A unique oxygen ligand environment facilitates water oxidation in hole-doped $\mathrm{IrNiO}_{\mathrm{x}}$ core-shell electrocatalysts. Nat. Catal. 2018, 1, 841-851.

(49) Li, X.; Su, X.; Pei, Y.; Liu, J.; Zheng, X.; Tang, K.; Guan, G.; Hao, X. Generation of edge dislocation defects in $\mathrm{Co}_{3} \mathrm{O}_{4}$ catalysts: an efficient tactic to improve catalytic activity for oxygen evolution. $J$. Mater. Chem. A 2019, 7, 10745-10750.

(50) Xu, T.; Zhou, X.; Jiang, Z.; Kuang, Q.; Xie, Z.; Zheng, L. Syntheses of Nano/Submicrostructured Metal Oxides with All Polar Surfaces Exposed via a Molten Salt Route. Cryst. Growth Des. 2009, 9, 192-196.

(51) Ren, G.; Li, Y.; Guo, Z.; Xiao, G.; Zhu, Y.; Dai, L.; Jiang, L. A bio-inspired $\mathrm{Co}_{3} \mathrm{O}_{4}$-polypyrrole-graphene complex as an efficient oxygen reduction catalyst in one-step ball milling. Nano Res. 2015, 8 , $3461-3471$

(52) Singh, R. N.; Pandey, J. P.; Singh, N. K.; Lal, B.; Chartier, P.; Koenig, J.-F. Sol-gel derived spinel $\mathrm{M}_{\mathrm{x}} \mathrm{Co}_{3-\mathrm{x}} \mathrm{O}_{4}(\mathrm{M}=\mathrm{Ni}, \mathrm{Cu})$ films and oxygen evolution. Electrochim. Acta 2000, 45, 1911-1919.

(53) Ji, G.; Gong, Z.; Zhu, W.; Zheng, M.; Liao, S.; Shen, K.; Liu, J.; $\mathrm{Cao}$ J. Simply synthesis of $\mathrm{Co}_{3} \mathrm{O}_{4}$ nanowire arrays using a solvent-free method. J. Alloys Compd. 2009, 476, 579-583.

(54) Wang, K.; Cao, Y.; Hu, J.; Li, Y.; Xie, J.; Jia, D. Solvent-Free Chemical Approach to Synthesize Various Morphological $\mathrm{Co}_{3} \mathrm{O}_{4}$ for CO Oxidation. ACS Appl. Mater. Interfaces 2017, 9, 16128-16137.

(55) Xu, R.; Zeng, H. C. Mechanistic Investigation on Salt-Mediated Formation of Free-Standing $\mathrm{Co}_{3} \mathrm{O}_{4}$ Nanocubes at $95{ }^{\circ} \mathrm{C}$. J. Phys. Chem. B 2003, 107, 926-930.

(56) Zhou, K.; Liu, J.; Wen, P.; Hu, Y.; Gui, Z. Morphologycontrolled synthesis of $\mathrm{Co}_{3} \mathrm{O}_{4}$ by one step template-free hydrothermal method. Mater. Res. Bull. 2015, 67, 87-93.

(57) Jadhav, A. R.; Puguan, J. M. C.; Kim, H. Microwave-Assisted Synthesis of a Stainless Steel Mesh-Supported $\mathrm{Co}_{3} \mathrm{O}_{4}$ Microrod Array As a Highly Efficient Catalyst for Electrochemical Water Oxidation. ACS Sustainable Chem. Eng. 2017, 5, 11069-11079.

(58) Duan, Y.; Zhang, Q.; Song, Z.; Wang, J.; Tang, X.; Liu, Q.; Zhang, T. Effect of preparation methods on the catalytic activity of $\mathrm{Co}_{3} \mathrm{O}_{4}$ for the decomposition of $\mathrm{N}_{2} \mathrm{O}$. Res. Chem. Intermed. 2017, 43, $7241-7255$

(59) Hammiche-Bellal, Y.; Djadoun, A.; Meddour-Boukhobza, L.; Benadda, A.; Auroux, A.; Berger, M.-H.; Mernache, F. Effect of the 
preparation method on the structural and catalytic properties of spinel cobalt-iron oxide. Mater. Chem. Phys. 2016, 177, 384-397.

(60) Zhu, Z.; Lu, G.; Zhang, Z.; Guo, Y.; Guo, Y.; Wang, Y. Highly Active and Stable $\mathrm{Co}_{3} \mathrm{O}_{4} / \mathrm{ZSM}-5$ Catalyst for Propane Oxidation: Effect of the Preparation Method. ACS Catal. 2013, 3, 1154-1164.

(61) Fukuzumi, S.; Jung, J.; Yamada, Y.; Kojima, T.; Nam, W. Homogeneous and Heterogeneous Photocatalytic Water Oxidation by Persulfate. Chem. - Asian J. 2016, 11, 1138-1150.

(62) Galán-Mascarós, J. R. Water Oxidation at Electrodes Modified with Earth-Abundant Transition-Metal Catalysts. ChemElectroChem 2015, 2, 37-50.

(63) Han, L.; Dong, S.; Wang, E. Transition-Metal (Co, Ni, and Fe)Based Electrocatalysts for the Water Oxidation Reaction. Adv. Mater. 2016, 28, 9266-9291.

(64) Kanan, M. W.; Nocera, D. G. In situ formation of an oxygenevolving catalyst in neutral water containing phosphate and $\mathrm{Co}^{2+}$. Science 2008, 321, 1072-1075.

(65) González-Flores, D.; Sánchez, I.; Zaharieva, I.; Klingan, K.; Heidkamp, J.; Chernev, P.; Menezes, P. W.; Driess, M.; Dau, H.; Montero, M. L. Heterogeneous water oxidation: surface activity versus amorphization activation in cobalt phosphate catalysts. Angew. Chem., Int. Ed. 2015, 54, 2472-2476.

(66) May, K. J.; Carlton, C. E.; Stoerzinger, K. A.; Risch, M.; Suntivich, J.; Lee, Y.-L.; Grimaud, A.; Shao-Horn, Y. Influence of Oxygen Evolution during Water Oxidation on the Surface of Perovskite Oxide Catalysts. J. Phys. Chem. Lett. 2012, 3, 3264-3270. (67) Risch, M.; Grimaud, A.; May, K. J.; Stoerzinger, K. A.; Chen, T. J.; Mansour, A. N.; Shao-Horn, Y. Structural Changes of Cobalt-Based Perovskites upon Water Oxidation Investigated by EXAFS. J. Phys. Chem. C 2013, 117, 8628-8635.

(68) Huang, J.; Du, X.; Feng, Y.; Zhao, Y.; Ding, Y. New insights into water oxidation reactions from photocatalysis, electrocatalysis to chemical catalysis: an example of iron-based oxides doped with foreign elements. Phys. Chem. Chem. Phys. 2016, 18, 9918-9921.

(69) Xiaoqiang, D.; Zhoufeng, X.; Yaqiong, G.; Yong, D. Polyoxometalate-based catalysts for photocatalytic, chemical catalytic and electrocatalytic water oxidation. Int. J. Hydrogen Energy 2017, 42, 24169-24175.

(70) Casas-Cabanas, M.; Binotto, G.; Larcher, D.; Lecup, A.; Giordani, V.; Tarascon, J.-M. Defect Chemistry and Catalytic Activity of Nanosized $\mathrm{Co}_{3} \mathrm{O}_{4}$. Chem. Mater. 2009, 21, 1939-1947.

(71) Scherrer, P. Bestimmung der inneren Struktur und der Größe von Kolloidteilchen mittels Röntgenstrahlen. Kolloidchemie - Ein Lehrbuch; Springer: Berlin, Heidelberg, 1912.

(72) Hadjiev, V. G.; Iliev, M. N.; Vergilov, I. V. The Raman spectra of $\mathrm{Co}_{3} \mathrm{O}_{4}$. J. Phys. C: Solid State Phys. 1988, 21, L199-L201.

(73) Gawali, S. R.; Gandhi, A. C.; Gaikwad, S. S.; Pant, J.; Chan, T.S.; Cheng, C.-L.; Ma, Y.-R.; Wu, S. Y. Role of cobalt cations in short range antiferromagnetic $\mathrm{Co}_{3} \mathrm{O}_{4}$ nanoparticles: a thermal treatment approach to affecting phonon and magnetic properties. Sci. Rep. 2018, 8, No. 249.

(74) Lorite, I.; Romero, J. J.; Fernández, J. F. Effects of the agglomeration state on the Raman properties of $\mathrm{Co}_{3} \mathrm{O}_{4}$ nanoparticles. J. Raman Spectrosc. 2012, 43, 1443-1448.

(75) Hongyan, X.; Jiangtao, D.; Zhenyin, H.; Libo, G.; Qiang, Z.; Jun, T.; Binzhen, Z.; Chenyang, X. A study of the growth process of $\mathrm{Co}_{3} \mathrm{O}_{4}$ microcrystals synthesized via a hydrothermal method. Cryst. Res. Technol. 2016, 51, 123-128.

(76) Gouadec, G.; Colomban, P. Raman Spectroscopy of nanomaterials. Prog. Cryst. Growth Charact. Mater. 2007, 53, 1-56.

(77) Dau, H.; Liebisch, P.; Haumann, M. X-ray absorption spectroscopy to analyze nuclear geometry and electronic structure of biological metal centers-potential and questions examined with special focus on the tetra-nuclear manganese complex of oxygenic photosynthesis. Anal. Bioanal. Chem. 2003, 376, 562-583.

(78) Sparks, T. D.; Gurlo, A.; Bekheet, M. F.; Gaultois, M. W.; Cherkashinin, G.; Laversenne, L.; Clarke, D. R. High-temperature structure of $\mathrm{Co}_{3} \mathrm{O}_{4}$ : Understanding spinel inversion using in situ and ex situ measurements. Phys. Rev. B 2019, 99, No. 104104.
(79) Sahoo, P.; Djieutedjeu, H.; Poudeu, P. F. P. $\mathrm{Co}_{3} \mathrm{O}_{4}$ nanostructures: the effect of synthesis conditions on particles size, magnetism and transport properties. J. Mater. Chem. A 2013, 1, 15022.

(80) NIST X-ray Photoelectron Spectroscopy Database, version 4.1; National Institute of Standards and Technology: Gathersburg, 2012. http://srdata.nist.

(81) Yang, J.; Liu, H.; Martens, W. N.; Frost, R. L. Synthesis and Characterization of Cobalt Hydroxide, Cobalt Oxyhydroxide, and Cobalt Oxide Nanodiscs. J. Phys. Chem. C 2010, 114, 111-119.

(82) Wagner, C. D. Auger lines in x-ray photoelectron spectrometry. Anal. Chem. 1972, 44, 967-973.

(83) Moretti, G. Auger parameter and Wagner plot in the characterization of chemical states by X-ray photoelectron spectroscopy: a review. J. Electron Spectrosc. Relat. Phenom. 1998, 95, 95-144.

(84) Kalyanasundaram, K. Photophysics, Photochemistry and Solar Energy Conversion with Tris(bipyridyl)ruthenium(II) and Its Analogues. Coord. Chem. Rev. 1982, 46, 159-244.

(85) Ambrosi, A.; Pumera, M. Multimaterial 3D-Printed Water Electrolyzer with Earth-Abundant Electrodeposited Catalysts. ACS Sustainable Chem. Eng. 2018, 6, 16968-16975.

(86) Song, F.; Busch, M. M.; Lassalle-Kaiser, B.; Hsu, C.-S.; Petkucheva, E.; Bensimon, M.; Chen, H. M.; Corminboeuf, C.; Hu, X. An Unconventional Iron Nickel Catalyst for the Oxygen Evolution Reaction. ACS Cent. Sci. 2019, 5, 558-568.

(87) Chen, Y.; Zhou, Q.; Zhao, G.; Yu, Z.; Wang, X.; Dou, S. X.; Sun, W. Electrochemically Inert g- $\mathrm{C}_{3} \mathrm{~N}_{4}$ Promotes Water Oxidation Catalysis. Adv. Funct. Mater. 2018, 28, No. 1705583.

(88) Chen, R.; Yang, C.; Cai, W.; Wang, H.-Y.; Miao, J.; Zhang, L.; Chen, S.; Liu, B. Use of Platinum as the Counter Electrode to Study the Activity of Nonprecious Metal Catalysts for the Hydrogen Evolution Reaction. ACS Energy Lett. 2017, 2, 1070-1075.

(89) Cherevko, S.; Zeradjanin, A. R.; Keeley, G. P.; Mayrhofer, K. J. J. A Comparative Study on Gold and Platinum Dissolution in Acidic and Alkaline Media. J. Electrochem. Soc. 2014, 161, H822-H830.

(90) Lopes, P. P.; Strmcnik, D.; Tripkovic, D.; Connell, J. G.; Stamenkovic, V.; Markovic, N. M. Relationships between Atomic Level Surface Structure and Stability/Activity of Platinum Surface Atoms in Aqueous Environments. ACS Catal. 2016, 6, 2536-2544.

(91) Rodriguez, P.; Tichelaar, F. D.; Koper, M. T. M.; Yanson, A. I. Cathodic corrosion as a facile and effective method to prepare clean metal alloy nanoparticles. J. Am. Chem. Soc. 2011, 133, 17626-17629.

(92) Wei, C.; Rao, R. R.; Peng, J.; Huang, B.; Stephens, I. E. L.; Risch, M.; Xu, Z. J.; Shao-Horn, Y. Recommended Practices and Benchmark Activity for Hydrogen and Oxygen Electrocatalysis in Water Splitting and Fuel Cells. Adv. Mater. 2019, No. 1806296.

(93) Tung, C.-W.; Hsu, Y.-Y.; Shen, Y.-P.; Zheng, Y.; Chan, T.-S.; Sheu, H.-S.; Cheng, Y.-C.; Chen, H. M. Reversible adapting layer produces robust single-crystal electrocatalyst for oxygen evolution. Nat. Commun. 2015, 6, No. 8106.

(94) Nair, V.; Deepthi, A. Cerium(IV) ammonium nitrate-a versatile single-electron oxidant. Chem. Rev. 2007, 107, 1862-1891.

(95) Wadsworth, E.; Duke, F. R.; Goetz, C. A. Present Status of Cerium(IV)-Cerium(III) Potentials. Anal. Chem. 1957, 29, 18241825.

(96) Hayes, S. A.; Yu, P.; O’Keefe, T. J.; O’Keefe, M. J.; Stoffer, J. O. The Phase Stability of Cerium Species in Aqueous Systems. J. Electrochem. Soc. 2002, 149, No. C623.

(97) Feng, C.; Zhang, J.; He, Y.; Zhong, C.; Hu, W.; Liu, L.; Deng, Y. Sub-3 nm $\mathrm{Co}_{3} \mathrm{O}_{4}$ nanofilms with enhanced supercapacitor properties. ACS Nano 2015, 9, 1730-1739.

(98) Jacot, R.; Moré, R.; Michalsky, R.; Steinfeld, A.; Patzke, G. R. Trends in the phase stability and thermochemical oxygen exchange of ceria doped with potentially tetravalent metals. J. Mater. Chem. A 2017, 5, 19901-19913.

(99) Ravel, B.; Newville, M. ATHENA, ARTEMIS, HEPHAESTUS: data analysis for X-ray absorption spectroscopy using IFEFFIT. J. Synchrotron Radiat. 2005, 12, 537-541. 
(100) Ankudinov, A. L.; Ravel, B.; Rehr, J. J.; Conradson, S. D. Realspace multiple-scattering calculation and interpretation of $\mathrm{x}$-rayabsorption near-edge structure. Phys. Rev. B 1998, 58, 7565-7576. 